\title{
When imperfect is preferred: the differential effect of aesthetic imperfections on choice of processed and unprocessed foods
}

\author{
Jacob Suher ${ }^{1} \cdot$ Courtney Szocs ${ }^{2} \cdot$ Koert van Ittersum ${ }^{3}$ \\ Received: 23 March 2020 / Accepted: 3 March 2021 / Published online: 22 May 2021 \\ (C) The Author(s) 2021
}

\begin{abstract}
Some companies design processed foods to contain aesthetic imperfections such as non-uniformities in shape, color, or texture. Simultaneously, consumers annually discard millions of pounds of unprocessed, safe-to-eat fruits and vegetables owing to aesthetic imperfections. Why design processed foods with aesthetic imperfections when people discard unprocessed foods because of them? Seven studies, including a choice study at a grocery store and an incentive-compatible study, show that the effect of aesthetic imperfections on consumer preferences depends on whether foods are unprocessed or processed. While imperfections negatively influence preferences for unprocessed foods, they positively influence preferences for processed foods. We attribute this preference shift to consumers making opposing inferences about the human care involved in producing aesthetically imperfect processed and unprocessed foods. Building on research highlighting the positive effects of human presence in production, we thus show that perceived care drives food choice. We discuss implications for product design, retail promotion, and sustainability.
\end{abstract}

Keywords Aesthetics $\cdot$ Food choices and waste $\cdot$ Human presence $\cdot$ Processed and unprocessed food

Producing uniform products is the goal of many food manufacturers (Process Engineering 2014) and has been a driving factor in the success of some restaurant chains (Myers 2015). However, although many companies strive for uniformity, others design products to contain aesthetic imperfections in the form of non-uniformities in shape, color, or texture. For example, an article in the popular press discusses how employees at Domino's Pizza shape dough into irregular rectangles when preparing Artisan Pizza, and engineers at Kraft

Rebecca Hamilton served as Area Editor for this article.

Koert van Ittersum

k.van.ittersum@rug.nl

Jacob Suher

jsuher@pdx.edu

Courtney Szocs

cszocs@1su.edu

1 School of Business, Portland State University, 631 SW Harrison Street, Portland, OR 97201, USA

2 E. J. Ourso College of Business, Louisiana State University, 501 South Quad Drive, Baton Rouge, LA 70803, USA

3 University of Groningen, Nettelbosje 2, 9747AE Groningen, Netherlands spent two years designing Oscar Meyer Carving Board Turkey so that slices vary in shape and thickness and look as if a butcher's knife cut the slices (Choi 2013). Another popular press article notes that instead of using the perfectly round egg patties from the Egg McMuffin, McDonald's created egg patties with a non-uniform shape when introducing the Egg White Delight McMuffin (Associated Press 2013). Conceivably, companies employ non-uniform shapes, colors, and textures to suggest the involvement of human care in producing the foods, as opposed to turning out foods that look entirely manufactured by machines. Food manufacturers and restaurant chains would benefit from knowing whether this conjecture is accurate and, more broadly, from understanding how aesthetic imperfections influence consumer preferences for processed foods.

Although food manufacturers sometimes design processed foods - that is, products altered from the state of whole ingredients (Szocs and Lefebvre 2016) - to contain aesthetic imperfections, farmers, retailers, and consumers discard millions of pounds of safe-to-eat unprocessed fruits and vegetables each year because they exhibit aesthetic imperfections (Bratskeir 2015). The United States annually wastes half of all produce grown, with an estimated value of $\$ 40$ billion (Buzby et al. 2011), often because retailers and consumers refuse to purchase fruits and vegetables that lack a highly 
symmetrical shape or a uniform texture (Block et al. 2016; Royte 2016). In light of this ironic and unsustainable phenomenon, this research addresses an important research question: Why do people dislike aesthetically imperfect unprocessed foods (e.g., blemished or misshapen fruits and vegetables), yet sometimes prefer processed foods (e.g., pizza, deli meat) that contain similar types of aesthetic imperfections?

We define aesthetically imperfect foods as foods that are non-uniform in shape, color, or texture and aesthetically perfect foods as foods that are relatively more uniform on these attributes (de Hooge et al. 2017; Loebnitz et al. 2015). Following past studies on imperfect foods, our focus is on aesthetic imperfections that are limited to the physical appearance of the food since other types of imperfections (e.g., wormholes, brown spots due to ripening, disease-related damage) may influence objective taste, flavor, or food quality (Grewal et al. 2019). Additionally, we examine the effects of aesthetic imperfections of the food itself, rather than flaws in the package. This distinction is important, as prior research suggests that package imperfections such as a dented package or a crooked label negatively affect consumer evaluations (White et al. 2016). Finally, we test the effects of aesthetic imperfections for processed and unprocessed foods for which the shape, color, or texture is not associated with a specific brand.

To address our research question, we draw on prior studies showing that human presence positively affects product evaluations (Abouab and Gomez 2015; Fuchs et al. 2015; Schroll et al. 2018) as well as research showing that consumers positively value care in food preparation (Zellner et al. 2011). We propose that consumers have opposing preferences for aesthetic imperfections in processed and unprocessed foods because they make different attributions for the level of human care (i.e., attention, concern, caution, and consideration; Morse et al. 1990; Nassauer 1988) involved in producing the foods. For processed foods, consumers attribute imperfections to higher levels of human care in production, whereas for unprocessed foods, consumers attribute imperfections to lower levels of human care in production. Given that prior research shows that human presence positively influences product evaluations, we predict that consumers are more likely to prefer an imperfect option when choosing between two processed foods than when choosing between two unprocessed foods.

Seeking initial support for our prediction, we conducted a pilot study where consumers indicated their preference for one of two foods differing in aesthetic perfection. Across eight pairs of processed and unprocessed foods, participants preferred the aesthetically imperfect option when choosing between two processed foods (e.g., pizzas) but preferred the aesthetically perfect option when choosing between two unprocessed foods (e.g., apples; see Web Appendix A for complete details of this pilot study).
Building on this pilot study, we develop a conceptual framework and report seven studies that make the following theoretical and substantive contributions. First, we identify when and why aesthetic imperfections positively influence food preferences. Using a variety of preference measures (e.g., choice, willingness to pay) and multiple sets of food stimuli, including some with one primary ingredient (e.g., apples and applesauce), we show that the effect of aesthetic imperfections on consumer preferences depends on whether foods are unprocessed or processed. While imperfections negatively influence preferences for unprocessed foods (e.g., apples), they positively influence preferences for processed foods (e.g., applesauce). This finding helps to reconcile findings from prior studies that have shown both positive and negative effects of aesthetics on consumer preferences. Specifically, ample research supports the lay belief that "beautiful is good" (Bloch 1995) and shows that consumers avoid aesthetically imperfect unprocessed foods (Baker 1999; Bunn et al. 1990; de Hooge et al. 2017; Grewal et al. 2019; Loebnitz et al. 2015) and prefer aesthetically enhanced non-food products (Hagtvedt and Patrick 2008). Other research reveals negative effects of enhanced aesthetics (e.g., Hoegg et al. 2010; $\mathrm{Wu}$ et al. 2017) and positive effects of careless mistakes that detract from product attractiveness (Reich et al. 2018a). Our research contributes by examining aesthetic imperfections rather than aesthetic enhancements and identifying when and why we observe a reversal in consumers' preference for imperfect foods.

Our second theoretical contribution is that we advance the stream of research showing that highlighting human presence positively influences product evaluations. Research in this stream finds that conveying human presence through explicit information, such as that a product is handmade (Fuchs et al. 2015) or that the creator had a lot of physical contact with the product during production (Newman and Bloom 2012), positively influences product evaluations. Other studies provide evidence that conveying human presence through implicit cues, such as organized product displays (Morales 2005) and fonts that appear to be handwritten, positively influences consumer evaluations (Schroll et al. 2018). Our research contributes to the literature on human presence by identifying aesthetic imperfections in processed and unprocessed foods as cues of human presence and, more specifically, care in food production. We offer and empirically verify a unique and unifying conceptual framework to explain these results, and we support our theory by testing competing mechanisms and boundary conditions of our findings.

Third, our conceptual framework, along with the corroborating evidence from our studies, suggest managerial tactics to increase sales of processed foods and decrease waste of aesthetically imperfect unprocessed foods. Our findings thus help reconcile conflicting practices in which some companies strive to create uniformity while others design products with 
non-uniformities in color, shape, or texture. We provide evidence of a potential benefit to designing processed foods with aesthetic imperfections. Our findings show that when including aesthetic imperfections in the product design is not possible or cost-effective, manufacturers and retailers can increase consumers' choice of a particular food by using communications that emphasize care in production (e.g., "made with care" labels). Finally, to help identify ways to reduce food waste (Block et al. 2016), which represents a large societallevel issue (Webster and Lusch 2013), we show how retailers can increase consumer preferences for aesthetically imperfect fruits and vegetables by highlighting the care involved in the growth and selection of these foods.

In the remainder of the paper, we review the literature on how aesthetics influence product evaluations and explain how inferences of human care in production drive the preference shift observed in the pilot study. We then describe a field study at a grocery retailer and six other studies, including one involving a consequential decision, which demonstrate the preference shift and provide evidence for the role of human care in production as the underlying mechanism. We conclude with a discussion of the implications of our findings and areas for future research.

\section{Theoretical background}

\section{Effects of aesthetics on product evaluations}

Consumers frequently rely on a product's appearance (Lawson 1983) when evaluating and choosing products (Bloch et al. 2003; Cox and Cox 2002; Reimann et al. 2010). To understand the effects of product aesthetics, we searched Google Scholar using the following terms: "imperfect food," "aesthetic imperfection," "ugly food," "suboptimal food," "beautiful food," "enhanced product aesthetics." We also reviewed manuscripts citing recent studies on the negative effects of enhanced aesthetics (Hoegg et al. 2010; Wu et al. 2017) and the positive effects of imperfections resulting from careless mistakes (Reich et al. 2018b) to identify studies published in academic journals that examined product aesthetics. As illustrated in Table 1, the majority of past studies on product aesthetics suggest that consumers respond favorably to an attractive appearance (Bloch 1995) and prefer products with enhanced aesthetics to those that are less enhanced or standardized (Reimann et al. 2010). Importantly, enhancing product aesthetics (e.g., creating symmetrical objects) can increase purchase intentions (Norman 2004) and willingness to pay (Bloch et al. 2003). In some cases, aesthetics are more important to product evaluations than performance or price (Yamamoto and Lambert 1994).

While those studies document positive effects of aesthetics, other studies reveal contexts in which enhanced aesthetics can surprisingly have a negative influence on product evaluations and consumption. Consumers who view a pair of products that differ in design and product feature attractiveness give lower performance ratings to a product with an objectively superior product feature when the feature is paired with an attractive as opposed to unattractive design (Hoegg et al. 2010). Additionally, consumers enjoy eating aesthetically enhanced cupcakes less than eating plain cupcakes since eating the aesthetically enhanced cupcake involves destroying effort (Wu et al. 2017, Study 2). Finally, related work shows that careless mistakes can increase product uniqueness and overall product value, even when the mistake negatively affects product aesthetics (e.g., a blurred photo) (Reich et al. 2018b, Study 6).

These mixed findings extend to the effects of aesthetics in the food domain.

\section{Positive and negative effects of aesthetics in the food domain}

Consumers' food evaluations and choices reflect the predominantly positive effects of enhanced aesthetics (Nenkov and Scott 2014; Zellner et al. 2011). For instance, consumers report greater liking and willingness to pay for a food presented neatly on a plate as opposed to in a messy way (Zellner et al. 2011). Consumers also have greater preference for foods in attractive packaging as opposed to primarily functional packaging (Reimann et al. 2010). Consistent with their preference for products with enhanced aesthetics, consumers reject fruits and vegetables that are blemished, misshapen, or marked by minor aesthetic imperfections (Baker 1999; Block et al. 2016; Bunn et al. 1990; de Hooge et al. 2017; Grewal et al. 2019; Loebnitz et al. 2015). Imperfections decrease consumers' willingness to pay for fruits (Roosen et al. 1998), and larger cosmetic defects exacerbate this effect (Yue et al. 2007). In general, aesthetic considerations (e.g., color, size, and a blemishfree appearance) are the factors that most commonly influence consumers' selection of produce (Baker 1999). Overall, past studies provide evidence that consumers positively evaluate foods with enhanced aesthetics, such as neat presentation and attractive packaging, and avoid aesthetically imperfect unprocessed fruits and vegetables.

However, the positive effects of enhanced aesthetics may not extend to all food types. For example, while consumers are more likely to choose a cupcake with frosting that looks like a rose rather than a cupcake with smooth frosting, they eat a smaller portion of the aesthetically enhanced cupcake and enjoy it less (Wu et al. 2017). This potential negative effect of enhanced aesthetics, combined with the fact that some companies intentionally produce foods to have a non-uniform appearance (Associated Press 2013; Choi 2013), raises an important question: Could aesthetic imperfections have a positive effect on preference for some types of food? 
Table 1 Research examining the positive and negative effects of product aesthetics

\begin{tabular}{|c|c|c|c|c|}
\hline & Study & Stimuli & & Key Finding \\
\hline & & $\begin{array}{l}\text { Unprocessed } \\
\text { Food }\end{array}$ & $\begin{array}{l}\text { Processed } \\
\text { Food }\end{array}$ & \\
\hline \multirow{7}{*}{$\begin{array}{l}\text { Positive Effects of } \\
\text { Aesthetic } \\
\text { Enhancement }\end{array}$} & Yamamoto and Lambert (1994) & & & Aesthetics can increase sales of industrial products. \\
\hline & Hagtvedt and Patrick (2008) & & & $\begin{array}{l}\text { Adding artwork to a non-food product influences } \\
\text { product evaluation as a result of perceptions of } \\
\text { product luxury. }\end{array}$ \\
\hline & Moshagen et al. (2009) & & & $\begin{array}{l}\text { Website aesthetics improve user performance and can } \\
\text { compensate for poor usability. }\end{array}$ \\
\hline & Hagtvedt and Patrick (2014) & & & $\begin{array}{l}\text { When products have a minor functionality issue, } \\
\text { enhanced (vs. non-enhanced) aesthetics increase } \\
\text { product evaluations. Aesthetics do not compensate } \\
\text { for major functionality issues. }\end{array}$ \\
\hline & Townsend (2017) & & & $\begin{array}{l}\text { Donation solicitations with enhanced aesthetics led to } \\
\text { greater donations when the aesthetics do not have } \\
\text { cost implications. When the aesthetics are costly, } \\
\text { enhanced aesthetics led to lower donations due to } \\
\text { greater perceived wastefulness. }\end{array}$ \\
\hline & Paaki et al. (2019) & $\mathrm{X}$ & $\mathrm{X}$ & $\begin{array}{l}\text { Consumers prefer lunches that contain a variety of } \\
\text { bright and contrasting colors. }\end{array}$ \\
\hline & Wiecek et al. (2019) & & & $\begin{array}{l}\text { Usage intensity is greater and switching is lower when } \\
\text { durable products have more (vs. less) aesthetic } \\
\text { designs. }\end{array}$ \\
\hline \multirow[t]{4}{*}{$\begin{array}{l}\text { Negative Effects of } \\
\text { Aesthetic } \\
\text { Enhancement }\end{array}$} & Hoegg et al. (2010) & & & $\begin{array}{l}\text { Consumers infer greater performance from less } \\
\text { attractive products that are superior on one attribute } \\
\text { than more attractive products that are inferior on that } \\
\text { same attribute. }\end{array}$ \\
\hline & Nenkov and Scott (2014) & & $\mathrm{X}$ & $\begin{array}{l}\text { Whimsically cute products prime thoughts of fun and } \\
\text { lead to more indulgent behavior than neutral or } \\
\text { Kindchenschema cute products. }\end{array}$ \\
\hline & Wu et al. (2017) & & $\mathrm{X}$ & $\begin{array}{l}\text { Individuals consume less, experience more negative } \\
\text { affect, and enjoy consumption less when products } \\
\text { have enhanced (vs. non-enhanced) aesthetics. These } \\
\text { effects are driven by perceptions of destroying } \\
\text { effort. }\end{array}$ \\
\hline & Crolic et al. (2019) & & & $\begin{array}{l}\text { Consumers expect attractive products with inferior } \\
\text { ratings on a given attribute to perform better than } \\
\text { unattractive products with superior ratings on the } \\
\text { attribute. }\end{array}$ \\
\hline $\begin{array}{l}\text { Positive Effects of } \\
\text { Imperfection }\end{array}$ & Reich et al. (2018a) & & $\mathrm{X}$ & $\begin{array}{l}\text { In Study 1a, consumers are more likely to choose a } \\
\text { chocolate bar and lasagna made by mistake than } \\
\text { made intentionally. Study } 6 \text { finds that mistakes } \\
\text { (blurriness) in photos positively impacted purchase } \\
\text { price. }\end{array}$ \\
\hline \multirow[t]{5}{*}{$\begin{array}{l}\text { Negative Effects of } \\
\text { Imperfection }\end{array}$} & $\begin{array}{l}\text { Baker (1999); Bunn et al. (1990); de Hooge et al. } \\
\text { (2017); Roosen et al. (1998); Schifferstein et al. } \\
\text { (2019); Steenkamp and van Trijp (1996); } \\
\text { Symmank et al. (2018); Yue et al. (2007) }\end{array}$ & $\mathrm{X}$ & & $\begin{array}{l}\text { Aesthetic imperfections decrease preference for } \\
\text { unprocessed foods. }\end{array}$ \\
\hline & Zellner et al. (2011) & & $\mathrm{X}$ & $\begin{array}{l}\text { Consumers like food presented neatly on a plate more } \\
\text { than the same food presented in a messy way. They } \\
\text { think more care was involved in preparing the } \\
\text { neatly presented food. }\end{array}$ \\
\hline & Loebnitz and Grunert (2015); Loebnitz et al. (2015) & $\mathrm{X}$ & & $\begin{array}{l}\text { Consumers prefer fruits and vegetables with normal } \\
\text { shapes. }\end{array}$ \\
\hline & Aschemann-Witzel et al. (2017) & $\mathrm{X}$ & $\mathrm{X}$ & $\begin{array}{l}\text { When consumers think they might waste food, they are } \\
\text { unlikely to purchase price discounted suboptimal } \\
\text { foods (e.g., apples with brown spots, misshapen } \\
\text { cucumbers, yogurt close to the expiration date, } \\
\text { broken cookies, juice in a dented package). }\end{array}$ \\
\hline & Helmert et al. (2017) & $\mathrm{X}$ & $\mathrm{X}$ & $\begin{array}{l}\text { Consumers are more likely to choose apples without } \\
\text { (vs. with) brown spots, normally (vs. abnormally) } \\
\text { shaped cucumbers, and cookies that are not (vs. are) } \\
\text { crumbled. Price badges that attract attention can } \\
\text { increase choice of suboptimal foods. }\end{array}$ \\
\hline
\end{tabular}


Table 1 (continued)

\begin{tabular}{|c|c|c|c|c|}
\hline & Study & Stimuli & & Key Finding \\
\hline & Aschemann-Witzel et al. (2018) & $\mathrm{X}$ & $\mathrm{X}$ & $\begin{array}{l}\text { Consumers are more likely to choose price discounted } \\
\text { suboptimal products (e.g., deformed potatoes, } \\
\text { bruised apples, peas in a dented can, bread close to } \\
\text { the expiration date) when a message about reducing } \\
\text { food waste is present compared to when it is not. }\end{array}$ \\
\hline & Loebnitz and Grunert (2018) & $\mathrm{X}$ & & $\begin{array}{l}\text { Consumers perceive abnormally shaped vegetables as } \\
\text { riskier than normally shaped vegetables. } \\
\text { Naturalness drives the effect of shape on risk } \\
\text { perception. }\end{array}$ \\
\hline & Aschemann-Witzel et al. (2019) & $\mathrm{X}$ & $\mathrm{X}$ & $\begin{array}{l}\text { Messages focused on money savings and emotional } \\
\text { appeals increase the likelihood of choosing } \\
\text { abnormally shaped potatoes and bread close to the } \\
\text { expiration date. Consumers are more likely to buy } \\
\text { the suboptimal bread from a supermarket than a } \\
\text { farmers market. }\end{array}$ \\
\hline & Cooremans and Geuens (2019) & $\mathrm{X}$ & & $\begin{array}{l}\text { Anthropomorphizing a misshapen (vs. regular) fruit or } \\
\text { vegetable increases choice. Affective reactions } \\
\text { drive the effect of anthropomorphism on choice. }\end{array}$ \\
\hline & Grewal et al. (2019) & $\mathrm{X}$ & & $\begin{array}{l}\text { Consumers are willing to pay less for unattractive (vs. } \\
\text { attractive) produce. Negative self-perceptions drive } \\
\text { the effects of imperfections on willingness to pay. }\end{array}$ \\
\hline & Koo et al. (2019) & $\mathrm{X}$ & & $\begin{array}{l}\text { Anthropomorphizing (vs. not) old produce increases } \\
\text { product evaluations. The effect is driven by warmth } \\
\text { evoked by the anthropomorphized food. }\end{array}$ \\
\hline \multirow{4}{*}{$\begin{array}{l}\text { Positive \& Negative } \\
\text { Effects of } \\
\text { Imperfection }\end{array}$} & van Giesen and de Hooge (2019) & $\mathrm{X}$ & & $\begin{array}{l}\text { The presence (vs. absence) of messages emphasizing } \\
\text { authenticity increase purchase intentions for } \\
\text { suboptimal produce. Messages emphasizing } \\
\text { sustainability increase purchase intentions when } \\
\text { combined with a price discount. }\end{array}$ \\
\hline & Hagen (2020) & $\mathrm{X}$ & & $\begin{array}{l}\text { Consumers are willing to pay more for a regular } \\
\text { shaped bell paper than a misshapen bell pepper } \\
\text { (Study 2). This effect is driven by perceived } \\
\text { healthiness. }\end{array}$ \\
\hline & Makhal et al. (2020) & $\mathrm{X}$ & & $\begin{array}{l}\text { Children respond positively to minor imperfections but } \\
\text { respond negatively to major imperfections. }\end{array}$ \\
\hline & The Present Research & $\mathrm{X}$ & $\mathrm{X}$ & $\begin{array}{l}\text { The present research provides evidence that the effect } \\
\text { of aesthetic imperfections on consumer preferences } \\
\text { depends on whether foods are unprocessed or } \\
\text { processed. While imperfections negatively } \\
\text { influence preferences for unprocessed foods, they } \\
\text { positively influence preferences for processed } \\
\text { foods. These findings are driven by perceived care } \\
\text { in production. }\end{array}$ \\
\hline
\end{tabular}

Our review of marketplace practices and academic literature reveals that food processing may influence the effect of aesthetic imperfections on consumer food preferences. In particular, studies highlighting the positive effects of enhanced food aesthetics primarily focus on unprocessed fruits and vegetables (Baker 1999; Grewal et al. 2019; Roosen et al. 1998). In contrast, research revealing negative effects of enhanced food aesthetics examined a processed food - a cupcake ( $\mathrm{Wu}$ et al. 2017). Moreover, the foods purposely designed to include aesthetic imperfections are all processed foods (e.g., egg patty, pizza, deli meat).

We propose that the effect of aesthetic imperfections on food preferences (e.g., choice, willingness to pay) depends on the whether a food is in a processed or unprocessed state (i.e., food processing). Next, we discuss how consumers' inferences about care in production for aesthetically imperfect unprocessed foods differ from inferences about care in production for aesthetically imperfect processed foods.

\section{Aesthetic imperfections as cues of care in food production}

Humans can be involved in food production to different extents. At one extreme, food production can occur without human presence, such as when fruits and vegetables grow in nature without human cultivation (Rozin 2005) or machines manufacture foods in an automated factory (Evans et al. 
2010). At the other extreme, humans might be present and involved in every step of the food production process.

We propose that, for both processed and unprocessed foods, aesthetic imperfections serve as cues of human presence and specifically care in production. As cues of human presence convey sensitivity, warmth, and contact (Grewal et al. 2020; Schroll et al. 2018; Short et al. 1976), we conceptualize human presence as care, in the form of attention, concern, caution, and consideration (Morse et al. 1990; Nassauer 1988). Next, we discuss how aesthetic imperfections convey information about the level of care in the production of unprocessed foods.

Unprocessed foods Consumers tend to be unaware of the natural variations in the appearance of fruits and vegetables (Loebnitz and Grunert 2018; Loebnitz et al. 2015) because foods with non-uniform shapes, colors, and textures (i.e., aesthetic imperfections) are frequently removed during initial stages of food production. During growth, farmers often cull fruits and vegetables with cosmetic defects. After harvest, farmers sort fruits and vegetables according to aesthetic grades before selling them to grocers, and then prior to sale, retail employees further sort out items with aesthetic imperfections before waxing or coating remaining foods (Phillips 2017). Only fruits and vegetables that meet the highest cosmetic standards for product uniformity end up on store displays (Royte 2016).

When consumers do encounter unprocessed fruits and vegetables with aesthetic imperfections, they attribute the nonuniformities to insect damage (Bunn et al. 1990), disease (Yue et al. 2007), rotting (Schifferstein et al. 2019), lack of safety (Baker 1999; Loebnitz and Grunert 2018), and reduced quality (Kader 1986). In light of these attributions, we propose that consumers will infer that unprocessed foods containing non-uniformities have been neglected (i.e., not cared for) during growth, cultivation, or sorting. Thus, the absence of aesthetic imperfections - or better, the presence of aesthetic perfection - signals care (i.e., attention, protection) in the production of unprocessed foods.

Processed foods While consumers may infer that aesthetically imperfect unprocessed foods have been neglected during production, we propose that consumers will infer that aesthetically imperfect processed foods have been cared for during production. Uniformity is the hallmark of mass production and machine manufacturing (Moisio et al. 2004; Murdoch and Miele 1999). For instance, every Oreo cookie has an identical blackish brown color, a perfectly round shape, and a cream-tocookie ratio of 29:71 (Ashe 2019). Similarly, McDonald's hamburger patties have an identical texture, thickness, and appearance - a uniformity achieved by machine production (Boerop and Moynihan 2020). In contrast, homemade or human-produced foods are original and unique, often containing non-uniformities in shape, color, or surface texture that result from variability involved in manual production (Arnould and Price 2006). Because consumers associate uniformity with mass production (Paxson 2013), popular press articles assert that some restaurants and food manufacturers purposely incorporate aesthetic imperfections into the design of foods so that the foods appear as though a human was involved in the production process (Associated Press 2013; Choi 2013).

In summary, we propose that when consumers encounter a pair of unprocessed foods, they will infer less care in production for the imperfect (vs. perfect) option. In contrast, when they encounter a pair of processed foods, they will infer greater care in production for the imperfect (vs. perfect) option. As a result, we predic:

H1: When evaluating two processed foods, consumers perceive greater care in production for the aesthetically imperfect (vs. perfect) option than when they are evaluating two unprocessed foods

\section{The influence of human care on food preferences}

If, as we propose, aesthetic imperfections signal different levels of care for processed and unprocessed foods, an important question arises: How will perceived care influence preferences (e.g., choice, willingness to pay) when consumers choose between perfect and imperfect versions of a food? Recent research suggests that consumers value human presence in the production of products (Grewal et al. 2020; Schroll et al. 2018). For instance, consumers evaluate products more favorably when marketers portray the product as handmade as opposed to machine-made (Fuchs et al. 2015). Consumers also value art and furniture more highly when they believe production involved extensive physical contact with a human producer than when they believe production involved little physical contact with the producer (Newman and Bloom 2012). While these examples reflect how explicit information about human presence in production positively influences product evaluations, evidence shows that implicit cues of human presence have a similarly positive effect. For instance, consumers evaluate products more favorably when the product's package displays a typeface that appears to be handwritten rather than machine-produced because the former suggests greater human contact (Schroll et al. 2018). Additionally, consumers are willing to pay more for products in neatly arranged displays because organization suggests an employee exerted effort to achieve order (Morales 2005). In the context of food, imagining a human picking, sorting, or processing grapes to produce grape juice can increase perceived naturalness (Abouab and Gomez 2015), which is a positive attribute for most food products (Rozin 2005). 
Consistent with the evidence that cues of human presence during production positively affect product evaluations (Fuchs et al. 2015; Schroll et al. 2018), we predict that care in production will positively influence preferences for both processed and unprocessed foods. Past studies support this prediction, finding that greater care in production and being able to trace a fruit or vegetable back to the farmer are key reasons consumers prefer locally produced food (Murdoch and Miele 1999; Reich et al. 2018b). In addition, evidence indicates that consumers evaluate processed foods produced by humans more positively than foods made by machines (Abouab and Gomez 2015) and negatively evaluate processed foods produced using industrial methods (Fernqvist and Ekelund 2014).

To summarize, Fig. 1 illustrates how food processing (i.e., processed vs. unprocessed) will influence consumer preferences for aesthetically perfect versus imperfect foods because of perceived human care in production. For unprocessed foods, we expect imperfections to signal a lack of human care in production, leading consumers to prefer a perfect rather than an imperfect version of a food. In contrast, for processed foods, we expect aesthetic imperfections to signal human care in production, leading to increased preference for the imperfect version.

H2: When evaluating two processed foods, consumers have a stronger preference for the aesthetically imperfect (vs. perfect) option than when they are evaluating two unprocessed foods

H3: Perceived human care mediates the effect of food processing on preference for the aesthetically imperfect (vs. perfect) food option

\section{Study 1: Evidence from a field study at a grocery store}

The purpose of Study 1 is to demonstrate the differential effects of aesthetic imperfections on choice of processed and unprocessed foods in a field setting with foods available for sale.

\section{Design, participants, and procedure}

Study 1 had a one-factor (food processing: processed vs. unprocessed) between-subjects design. Shoppers $(N=103)$ who approached the sampling counter at a grocery store that was a branch of a chain of medium-sized supermarkets headquartered in the Pacific Northwest served as participants. The store sells conventional merchandise as well as local and organic products. The sampling counter is near the main entrance and regularly offers free coffee and food samples. Shoppers who approached the counter chose between relatively perfect and imperfect versions of a processed food (peanut butter cookies) or an unprocessed food (mandarin oranges). Web Appendix B provides images. The food option (processed vs. unprocessed) and positioning of the items were rotated approximately every 25 people. Research assistants discreetly recorded choice of the aesthetically perfect or imperfect option after the shopper left the counter.

\section{Results}

Consistent with our prediction, the majority of shoppers (38 of 53 , or $71.7 \%$ ) who were offered the processed food pair (the peanut butter cookies) chose the imperfect option, whereas a minority of shoppers ( 7 of 50 , or $14.0 \%$ ) offered the unprocessed food pair (the mandarin oranges) chose the imperfect option $\left(\chi^{2}(1, \mathrm{~N}=103)=34.82, p<.001\right)$.

\section{Discussion}

Using real food items available for purchase in a grocery store, the results of Study 1 show that when choosing between two unprocessed foods, shoppers prefer the aesthetically perfect option. However, as predicted by $\mathrm{H} 2$, this preference shifts toward the imperfect option when the choice is between two processed foods. One shortcoming of Study 1 is that the processed foods were multi-ingredient cooked foods whereas the unprocessed foods were single-ingredient whole foods. A second shortcoming is that the imperfections varied across the processed and unprocessed foods. Specifically, the unprocessed foods varied primarily in terms of uniformity of color, whereas the processed foods varied in terms of shape and texture. Next, Study 2 addresses these shortcomings through the use of stimuli created by a professional photographer, while maintaining ecological validity through incentivecompatible product evaluations.

\section{Study 2: Effects of aesthetic imperfections on willingness to pay for food subscription boxes}

Besides addressing the limitations of Study 1, Study 2 also extends our investigation to a different behavioral outcome, willingness to pay (WTP) for food-subscription boxes, using an incentive-compatible BDM procedure (Becker et al. 1964).

\section{Design, participants, and procedure}

This pre-registered study https://aspredicted.org/dq2fk.pdf had a 2 (food processing: processed vs. unprocessed) $\times 2$ (items: perfect foods vs. imperfect foods) design. The first factor was between subjects and the second factor was within subjects. 
Fig. 1 Summary of conceptual framework

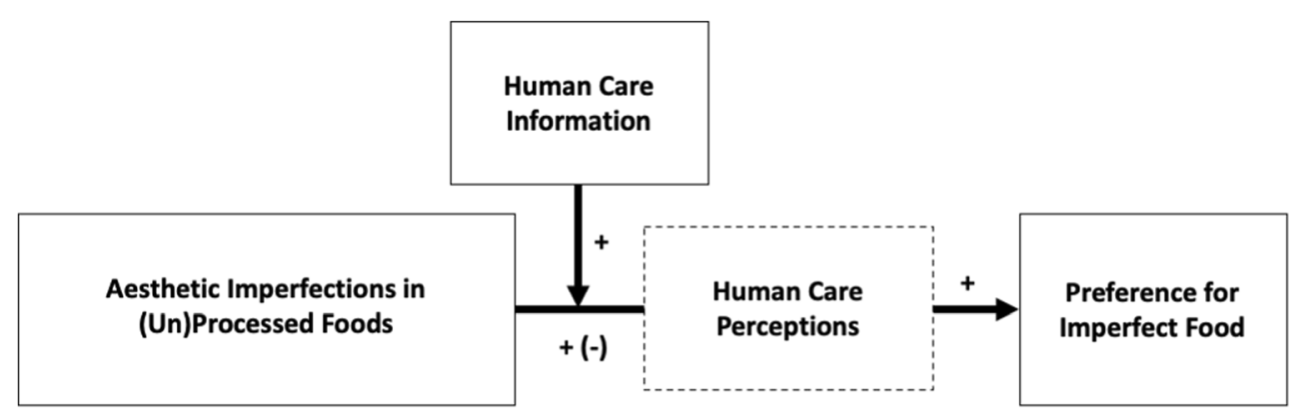

We contracted a professional photographer to create a pair of food subscription boxes containing unprocessed foods (i.e., apples, potatoes) and a pair of food subscription boxes containing processed foods (i.e., applesauce, fries). We instructed the photographer to digitally alter the uniformity of the texture, color, and shape of the food items so that one box within each pair contained more aesthetically perfect items and the other box contained more aesthetically imperfect items. The foods were displayed in front of a food delivery box labeled as "Quick Food" and affixed with an FDA label. See Appendix 1 for images of the stimuli.

We informed participants that they will be asked to evaluate food delivery services from two different suppliers, Supplier A and Supplier B, and will actually receive the foods at the price that they bid if their entry is selected and greater than the randomly selected price. Depending on the food processing condition, participants then viewed a pair of food boxes containing either processed or unprocessed foods. We measured WTP for each food box on a scale from zero to 10 dollars using the question, "What is the most you would pay for one box from Quick Food Supplier A (B) containing the foods pictured above?". In this and all subsequent studies, participants reported basic demographics (i.e., gender, age) following the dependent measures.

In addition, in this and all subsequent studies, we counterbalanced the lateral position of the perfect foods and the imperfect foods so that half of participants saw a pair of options where the imperfect option was A and the other half saw a pair of options where the imperfect option was B. As the lateral position of the options did not have a consistent effect on any of the measured variables across studies, we collapsed the data across lateral position and present the results as if the imperfect foods were shown as option B in this and all subsequent studies.

We recruited 304 student participants. In accordance with our pre-registered exclusion criteria, we excluded individuals who did not finish the survey as well as individuals who indicated they experienced issues with the images loading, leaving a final sample of 289 (46.7\% male, 53.3\% females; $\mathrm{M}_{\text {age }}=20.91$ ).

\section{Results}

We tested the effect of food processing on participants' WTP for the food boxes using a repeated measures analysis of variance (ANOVA) with one within-subject factor (items: perfect foods vs. imperfect foods) and one between-subjects factor (food processing: processed vs. unprocessed). In support of $\mathrm{H} 2$, there was a significant interaction between items and food processing $(\mathrm{F}(1,287)=138.49, p<.001)$ indicating that the effect of aesthetic perfection on WTP depended on food processing. In addition, there was a significant main effect of food aesthetics $\left(\mathrm{M}_{\text {perfect }}=\$ 4.84\right.$ vs. $\mathrm{M}_{\text {imperfect }}=\$ 3.89 ; \mathrm{F}(1,287)=$ $64.55, p<.001)$. Follow-up planned contrast tests showed participants who viewed boxes of processed foods were willing to pay more for the box containing imperfect options $\left(\mathrm{M}_{\text {perfect }}=\$ 4.23\right.$ vs. $\mathrm{M}_{\text {imperfect }}=\$ 4.67 ; \mathrm{F}(1,287)=6.67$, $p=.010)$. In contrast, participants who viewed boxes of unprocessed foods were willing to pay more for the box containing perfect options $\left(\mathrm{M}_{\text {perfect }}=\$ 5.44\right.$ vs. $\mathrm{M}_{\text {imperfect }}=\$ 3.10 ; \mathrm{F}$ $(1,287)=205.31, p<.001)$. Web Appendix C reports consistent results using overall evaluations collected after the WTP measures.

\section{Discussion}

Consistent with the results of Study 1, the results of Study 2 provide evidence for the managerial implications of our findings by extending our investigation to another aspect of preference (i.e., incentive-compatible WTP) and a new population of participants (i.e., undergraduate students). The remaining studies (Studies 3-6) examine the process driving the effects of food processing on preference for aesthetically perfect (vs. imperfect) options. We next discuss the creation of stimuli for these studies.

\section{Stimuli creation}

Studies 3, 4, and 5 relied on photographs of sets of food items that varied in terms of food processing (processed vs. unprocessed) as well as aesthetic perfection (perfect vs. imperfect). To create stimuli for the studies, we contracted a professional photographer, who was blind to the experimental hypotheses. 
The photographer first took pictures of a set of aesthetically perfect food items purchased from a grocery store (i.e., an apple, a single serving of applesauce, potatoes, potato chips, fries) and then digitally manipulated the appearance of the food items to make them aesthetically imperfect (i.e., nonuniform in shape, color, or texture).

Using Prolific online panelists, we then conducted a pretest to ensure that participants perceived the food items as different in terms of aesthetic perfection. Panelists $(N=500 ; 49.8 \%$ female, $49.8 \%$ male, $0.4 \%$ preferred not to say; $\mathrm{M}_{\text {age }}=$ 32.52) were randomly assigned to view an image of a food item and then respond to measures of aesthetic perfection (i.e., uniform shape, color, and texture) and presumed taste (i.e., sweet, bitter, sour, savory, and creamy). Appendix 2 presents the measures. We averaged the three items for each type of aesthetic perfection to create indexes for shape $(\alpha=.92)$, color ( $\alpha=.88$ ), and texture ( $\alpha=.88$ ). Overall, we found significant differences in aesthetic perfection between the perfect and imperfect versions of each food pair (Table 2 shows stimuli and pretest results for the apple and potato stimuli used in Studies 3a, 3b, 4, and 5). Importantly, we found nonsignificant differences for the presumed taste items between the perfect and imperfect version of each food pair (except for one item in one food pair; see Web Appendix D for complete results).

\section{Study 3a: Effects of aesthetic imperfections on preference for processed and unprocessed foods}

Study $3 \mathrm{a}$ tests H1-3. We predict that consumers will infer greater care in production of aesthetically imperfect processed foods than imperfect unprocessed foods (H1). Additionally, consumers will be more likely to choose an imperfect option when choosing between two processed foods than when choosing between two unprocessed foods (H2). Finally, perceived human care in production will drive choice of processed and unprocessed foods (H3).

\section{Design, participants, and procedure}

This pre-registered study https://aspredicted.org/sj4jn.pdf had two between-subjects conditions (food processing: processed vs. unprocessed). We used the potato/fry food sets from the stimuli-creation pretest. Participants viewed a pair of potatoes or fries and indicated their preference $(1=$ definitely A, $7=$ definitely B). The pair of foods contained a relatively more aesthetically perfect option and a relatively more aesthetically imperfect option (as seen in Table 2 and discussed in the previous section).

After indicating their preference, participants responded to three items related to human care in production: "Which food received more human care when it was produced?", "Which food received more human attention when it was produced?", and "Which food was neglected by a human (i.e., not cared for by a human) during the production process?" (reverse-coded) ( 1 = definitely A, 7 = definitely B; adapted from Zellner et al. 2011). Participants then clicked to the next page where they saw the same food pair and were asked to indicate which food was healthier, more unique, safer, and more artisanal $(1=$ definitely A, 7 = definitely B).

We recruited 200 Prolific panelists. In accordance with our pre-registered exclusion criteria, we excluded individuals who did not finish the survey as well as individuals who indicated they experienced issues with the images loading, leaving a final sample of 188 (45.7\% female, $53.7 \%$ male, $0.5 \%$ did not indicate gender; $\mathrm{M}_{\mathrm{age}}=33.32$ ).

\section{Results}

Human care The three human-care items (the third item was reverse-coded) were averaged to create an index $(\alpha=.89)$ with responses coded so that higher values indicate greater human care for the imperfect option in each food set. A oneway ANOVA of food processing on the human care index revealed that individuals who viewed the processed foods (i.e., fries) rated the imperfect option as receiving more human care than individuals who viewed the unprocessed foods (i.e., potatoes $)\left(\mathrm{M}_{\text {processed }}=3.88\right.$ vs. $\mathrm{M}_{\text {unprocessed }}=2.70 ; \mathrm{F}(1$, $186)=25.89, p<.001)$, thereby supporting $\mathrm{H} 1$.

Preference In support of H2, individuals who viewed the processed foods had a greater preference for the imperfect option than individuals who viewed the unprocessed foods $\left(\mathrm{M}_{\text {processed }}=4.63\right.$ vs. $\mathrm{M}_{\text {unprocessed }}=2.03 ; \mathrm{F}(1,186)=88.06$, $p<.001)$.

Mediation by human care To examine the indirect effects of food processing on preference for the imperfect option through perceptions of human care (H3), we used PROCESS Model 4 with 5000 bootstrap samples (Hayes 2012). This simple mediation model is appropriate because we manipulate a single factor, food processing, and measure preference and human care perceptions between the perfect and imperfect food options. The mediation test revealed a direct effect of food processing on preference for the imperfect food option ( $\beta=1.76 \mathrm{SE}=0.24,95 \% \mathrm{CI}$ : $[1.29,2.24])$ and an indirect effect of food processing on preference through human care $(\beta=0.84, \mathrm{SE}=0.17,95 \% \mathrm{CI}$ : $[0.51,1.18])$. In support of $\mathrm{H} 3$, this pattern of results suggests that perceived human care mediates preference for an aesthetically imperfect (vs. perfect) version of the same food for both processed and unprocessed food stimuli.

Alternative explanations As compared to individuals who viewed the unprocessed foods, individuals who viewed the 
Table 2 Examples of food stimuli in Studies 3a-5 and results of stimuli creation pretest

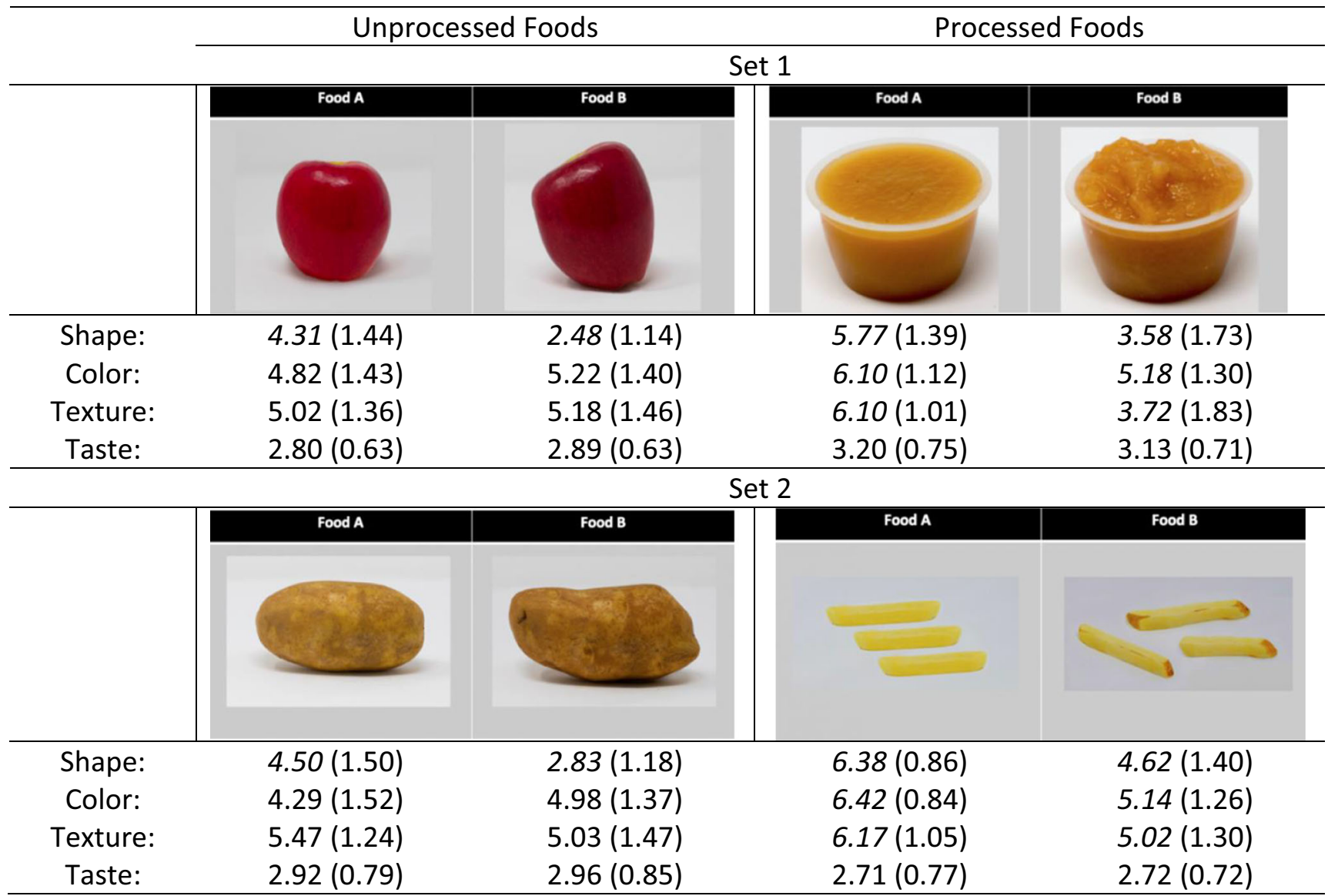

Note: Italicized ratings indicate significant $(p<.05)$ differences between the perfect and imperfect versions of a food pair on measures of aesthetic imperfections (e.g., The shape/color/texture of the food is uniform/consistent/varies [reversed] $1=$ Strongly Disagree, $7=$ Strongly Agree). Standard deviations in parentheses. Imperfect option shown as Food B. The taste measure is an average of the five items; individual item results are in Web Appendix D

processed foods rated the imperfect option as safer $\left(\mathrm{M}_{\text {processed }}=\right.$ 4.00 vs. $\left.\mathrm{M}_{\text {unprocessed }}=3.28 ; \mathrm{F}(1,186)=9.58, p=.002\right)$, healthier $\left(\mathrm{M}_{\text {processed }}=4.23\right.$ vs. $\mathrm{M}_{\text {unprocessed }}=3.40 ; \mathrm{F}(1,186)=13.16$, $p<.001)$, and more artisanal $\left(\mathrm{M}_{\text {processed }}=4.51\right.$ vs. $\left.\mathrm{M}_{\text {unprocessed }}=3.81 ; \mathrm{F}(1,186)=6.08, p=.015\right)$. The effect of food processing on perceived uniqueness was non-significant $(\mathrm{F}(1,186)=0.31, p=.580)$.

To examine the dominant mechanism driving preference for imperfect processed and unprocessed foods, we ran parallel mediation (PROCESS Model 4 with 5000 bootstrapped samples) with food processing as the independent variable, preference for the imperfect option as the dependent variable, and care, uniqueness, healthiness, artisanality, and safety as mediators. The results showed that the confidence intervals associated with care and artisanality did not include zero, suggesting mediation (care: $\beta=0.48, \mathrm{SE}=0.14,95 \% \mathrm{CI}$ : $[0.24,0.77]$; artisanal: $\beta=0.16$, $\mathrm{SE}=0.08,95 \% \mathrm{CI}:[0.03,0.34])$. The coefficient for care was larger than the coefficient for artisanality $(\beta=-.36, \mathrm{SE}=.15$, $95 \% \mathrm{CI}:[-.67,-.09])$, suggesting that care was the more dominant process driving the effects of food processing on preference for the imperfect option. The confidence intervals associated with uniqueness $(\beta=0.00, \mathrm{SE}=0.02,95 \% \mathrm{CI}$ : $[-0.03,0.04])$, healthiness $(\beta=0.18, \mathrm{SE}=0.11,95 \% \mathrm{CI}:[-0.04,0.40])$, and safety $(\beta=0.10, \mathrm{SE}=0.09,95 \% \mathrm{CI}:[-0.05,0.32])$ included zero.

Next, Study 3b replicates the results of Study $3 \mathrm{a}$ with another set of stimuli and shows that care is a human trait.

\section{Study 3b: Evidence that care is uniquely human}

The objective of Study $3 \mathrm{~b}$ is to provide empirical evidence that care is a human trait (McCance et al. 1997). We would not expect attention, concern, or consideration (i.e., care) from a well-designed machine to have the same effects as human care. Additionally, while consumers respond positively to human presence during production (Fuchs et al. 2015), they are generally less positive about machine production (Schroll et al. 2018). Thus, the pattern of effects for machine care should differ from that for human care. 


\section{Design, participants, and procedure}

Study $3 \mathrm{~b}$ had a 2 (food processing: unprocessed vs. processed) $\times 2$ (food set: apple-based products vs. potatobased products) between-subjects design. Participants viewed a pair of apple or potato-based products (see Table 2) containing a relatively more aesthetically perfect option and a relatively more imperfect option and indicated their preference using the same measure as Study $3 \mathrm{a}$. After indicating their preference, participants responded to the same three human care in production items used in Study $3 \mathrm{a}$ and then responded to the following three items related to machine care in production $(1=$ definitely $\mathrm{A}$, 7 = definitely B): "Which food received more machine care when it was produced?", "Which food received more machine attention when it was produced?", and "Which food was neglected by a machine (i.e., not cared for by a machine) during the production process?" (reverse-coded). Members of Prolific's online panel ( $N=206 ; 37.4 \%$ female, $62.6 \%$ male; $\left.M_{\text {age }}=34.54\right)$ participated in exchange for monetary compensation.

Human care A (food processing) $\mathrm{x}$ (food set) ANOVA on the human care index $(\alpha=.86)$ revealed only a main effect of food processing $(\mathrm{F}(1,202)=29.03, p<.001)$, which showed that, consistent with H1, participants who viewed the processed food sets rated the imperfect option as receiving more human care in production than participants who viewed the unprocessed food sets $\left(\mathrm{M}_{\text {processed }}=4.11\right.$ vs. $\left.\mathrm{M}_{\text {unprocessed }}=2.95\right)$. The main effect of food set ( $\mathrm{F}(1$, $202)=0.01, p=.912)$ and the interaction $(\mathrm{F}(1,202)=$ $0.44, p=.510$ ) were non-significant.

Machine care A (food processing) $\mathrm{x}$ (food set) ANOVA on the machine care index $(\alpha=.75$, with responses coded so that higher values indicate greater machine care for the imperfect option in each food set), revealed only a significant main effect of machine care, which showed that participants who viewed the processed food set rated the imperfect option as receiving less machine care in production than individuals who viewed the unprocessed food set $\left(\mathrm{M}_{\text {processed }}=2.83\right.$ vs. $\left.\mathrm{M}_{\text {unprocessed }}=3.30 ; \mathrm{F}(1,202)=6.13, p=.014\right)$. The main effect of food set $(\mathrm{F}(1,202)=1.59, p=.209)$ and the interaction were non-significant $(\mathrm{F}(1,202)=0.01, p=.943)$.

Preference A (food processing) x (food set) ANOVA on preference for the imperfect option revealed that, in support of $\mathrm{H} 2$, individuals who viewed the processed food set had a stronger preference for the imperfect option than individuals who viewed the unprocessed food set $\left(\mathrm{M}_{\text {processed }}=4.10 \mathrm{vs}\right.$. $\left.\mathrm{M}_{\text {unprocessed }}=2.44 ; \mathrm{F}(1,202)=32.69, p<.001\right)$. The main effect of food set $(\mathrm{F}(1,202)=0.80, p=.371)$ and the interaction $(\mathrm{F}(1,202)=1.29, p=.257)$ were non-significant.
Mediation by human and machine care We used a parallel multiple mediation test- PROCESS Model 4 with 5000 bootstrap samples - to examine the indirect effects of food processing on preference for the imperfect option through perceptions of human care and machine care. First, the model revealed a direct effect of food processing on preference for the imperfect option $(\beta=0.51, \mathrm{SE}=0.14,95 \%$ CI: $[0.79,0.23])$. Second, the model showed an indirect effect of food processing on preference through human care $(\beta=0.36, \mathrm{SE}=0.09,95 \% \mathrm{CI}:[0.54,0.21])$. The indirect effect of food processing on preference through machine care was non-significant $(\beta=-0.04, \mathrm{SE}=0.03,95 \%$ CI: $[0.01,-0.11])$. Hence, consistent with H3, perceived human care mediates preference for imperfect processed and unprocessed foods.

\section{Discussion}

The results of Studies $3 a$ and $3 b$ are consistent with the results of our incentive-compatible studies and explain why aesthetic imperfections differentially influence consumer preference for processed and unprocessed foods. We find that when evaluating two unprocessed foods consumers prefer the aesthetically perfect option, but when evaluating two processed foods preferences shift toward the aesthetically imperfect option. In addition, Studies $3 \mathrm{a}$ and $3 \mathrm{~b}$ show that human care, rather than machine care, safety, healthiness, uniqueness, or artisanality, is the dominant process driving the effect of food processing on preferences for the imperfect option.

\section{Study 4: Effects of human care information}

Whereas Studies 3a and 3b measure human care, Study 4 investigates the effect of human care on food preferences by manipulating care. If, as we are predicting, human care in production drives preferences, then providing information about the care involved in producing a food should increase preference for that option (i.e., there should be a main effect of care information). Hence, we are predicting that in the absence of additional care information, individuals will have a stronger preference for the imperfect option with processed (vs. unprocessed) foods (as in Studies 1, 2, and 3). Informing individuals that the imperfect option received human care in production will lead to increased preference for the imperfect option compared to presentation of the foods without explicit care information.

H4: Highlighting human care in production of the imperfect option leads to a stronger preference for the imperfect (vs. perfect) food option as compared to a control condition 
As human presence is a necessary condition for care to exist (McCance et al. 1997), telling consumers a machine carefully performed the same steps in production should lead to a different pattern of results. Specifically, informing participants that a machine cared for an imperfect food during production should negatively impact preferences for that food. To corroborate this, Study 4 also tests the effect of providing machine care information on preference for imperfect (vs. perfect) foods.

In Studies 4 and 5, we manipulate care information for only the imperfect foods to test whether highlighting human care in production increases preference for the imperfect (vs. perfect) food option (H4). In Study 6, we manipulate care information for both the perfect and imperfect food options to examine our process mechanism by testing whether explicit care information can attenuate the impact of processing on food choice.

\section{Design, participants, and procedure}

Study 4 had a 2 (food processing: processed vs. unprocessed) $\times 3$ (information on imperfect: human care vs. machine care vs. control/none) between-subjects design. We randomly assigned Prolific panelists $(N=300 ; 48.3 \%$ female, $51.7 \%$ male; $\mathrm{M}_{\text {age }}=32.68$ ) to view a pair of potato-based food products from Study 3. In the processed (unprocessed) condition, participants viewed two versions of fries (potatoes). The aesthetically imperfect fries had a less uniform color than the aesthetically perfect fries owing to the presence of some potato skin. The aesthetically imperfect potato had a less uniform shape than the aesthetically perfect potato. Then, based on the information on imperfect condition, the survey displayed a description of the production process under each of the food images. As shown in Web Appendix E, participants in the human care and machine care conditions read that the imperfect items received human care or machine care at different steps in the production process. The perfect food always had a description of the production process without the mention of human care or machine care. In the control conditions, the steps in the production process appeared without any human care or machine care information for all foods. These manipulations are consistent with prior work (Abouab and Gomez 2015). In addition, a pretest showed that participants perceived our manipulations as intended (see Web Appendix F). After viewing the pair of foods and the production information, participants indicated their preferred food option.

\section{Results}

We regressed food choice $(1=$ imperfect, $0=$ perfect $)$ on a contrast-coded variable for food processing ( $1=$ processed, $-1=$ unprocessed), two dummy coded variables for information on imperfect with the control condition as the reference level, and the two-way interactions between food processing and the information on imperfect dummy codes using a logistic regression.

First, in support of $\mathrm{H} 2$ and as illustrated in Fig. 2, we find a positive simple effect of food processing within the control condition $\left(\beta=1.87, \chi^{2}(293)=35.95, p<.001\right)$. In addition, changing the reference level for the information on imperfect variables revealed a positive simple effect of food processing within the human care information condition $\left(\beta=0.78, \chi^{2}\right.$ $(293)=10.52, p=.001)$ and the machine care information condition $\left(\beta=1.50, \chi^{2}(293)=20.55, p<.001\right)$. As predicted by $\mathrm{H} 2$, this provides evidence that individuals were more likely to choose the imperfect (vs. perfect) option for processed foods across all levels of care information.

Next, we find a negative interaction between food processing and the human care dummy code $\left(\beta=-1.09, \chi^{2}(293)=\right.$ $7.69, p=.006)$ and, in support of $\mathrm{H} 4$, there was a positive main effect of the human care dummy code $\left(\beta=1.43, \chi^{2}\right.$ $(293)=13.30, p<.001)$. Follow-up planned contrast tests revealed that the simple effect of human care as compared to no information was positive for the unprocessed foods $\left(\mathrm{P}_{\text {human_care }}=52.0 \%\right.$ vs. $\mathrm{P}_{\text {control }}=8.0 \% ; \beta=2.52, \chi^{2}(293)=$ $18.08, \bar{p}<.001)$ indicating that providing information about the human care involved in producing the imperfect food increased preference for that option relative to when no information was provided. With processed foods, we are predicting that consumers infer greater care in production for the imperfect (vs. perfect) option. Thus, providing information about the care involved in producing the imperfect option did not increase preference relative to the control condition $\left(\mathrm{P}_{\text {human_care }}=83.7 \%\right.$ vs. $\mathrm{P}_{\text {control }}=78.4 \% ; \beta=0.34, \chi^{2}$ $(293)=0.44, p=.505)$.

Finally, consistent with our theorizing, we find a nonsignificant interaction between food processing and the machine care dummy code $\left(\beta=-0.37, \chi^{2}(293)=0.67, p=.414\right)$ and a non-significant main effect of the machine care dummy code $\left(\beta=-0.68, \chi^{2}(293)=2.24, p=.134\right)$. The simple effect of machine care as compared to no information was nonsignificant for the unprocessed foods $\left(\mathrm{P}_{\text {machine_care }}=6.0 \%\right.$; $\left.\beta=-0.31, \chi^{2}(293)=0.15, p=.696\right)$. For processed foods, the simple effect of machine care was negative, indicating that providing information about the machine care involved in producing the imperfect option decreased preference for that option relative to the no-information condition $\left(\mathrm{P}_{\text {machine care }}=\right.$ $\left.56.0 \% ; \beta=-1.05, \chi^{2}(293)=5.59, p=.018\right)$.

\section{Discussion}

In support of $\mathrm{H} 4$, the results of Study 4 provide evidence that human care information increases preferences for imperfect foods as compared to the no-information condition. In addition, Web Appendix G reports consistent results from a replication of Study 4 with apples and applesauce as the unprocessed and processed foods. We performed this replication 
Fig. 2 Study 4 results

because, unlike an unprocessed potato, an unprocessed apple is ready for immediate consumption. We also conducted a posttest with apple products to rule out alternative explanations related to calorie content, contamination, freshness, uniqueness, and perceived scarcity. Collectively, Study 4 and its replication show that in the absence of any care information, individuals prefer imperfect (vs. perfect) processed foods, but prefer perfect (vs. imperfect) unprocessed foods. Furthermore, providing information about the human care involved in making or producing an aesthetically imperfect food can increase preference for that option. In contrast, informing participants that a machine performed the same steps in production can decrease preference for the imperfect option.

\section{Study 5: Effects of human presence with and without care}

Building on Study 4, Study 5 tests whether human care rather than mere human involvement (i.e., mere effort or carelessness; Franke and Schreier 2010) drives consumer preferences between aesthetically perfect and imperfect versions of the same food. If our prediction is correct and human care is driving the effects of food processing on consumer preferences, then human involvement without attention, concern, or caution (i.e., care) should not have a positive effect on preference for the imperfect (vs. perfect) option as human care did in Study 4.

\section{Design, participants, and procedure}

Study 5 had a 2 (food processing: unprocessed vs. processed) $\times 3$ (information on imperfect: human care vs. human carelessness vs. control/none) between-subjects design. Members
Unprocessed Food $\quad$ Processed Food

$100 \%$

$90 \%$

$80 \%$

$70 \%$

$60 \%$

$50 \%$

$40 \%$

$30 \%$

$20 \%$

$10 \%$

$0 \%$
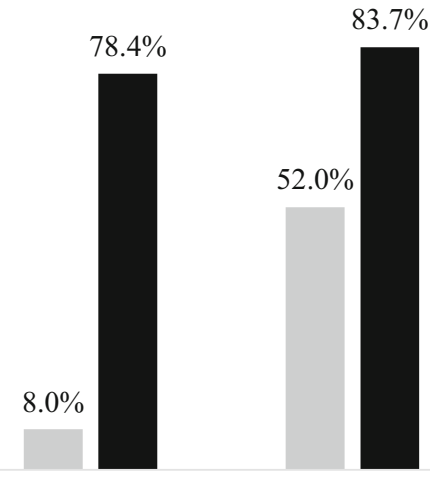

Human Care

Control/None
Information on Imperfect Option

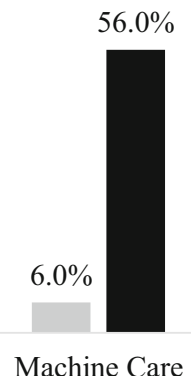

of the Prolific online panel $(N=300 ; 51.0 \%$ female, $47.3 \%$ male, $1.7 \%$ preferred not to say; $\mathrm{M}_{\text {age }}=31.87$ ) saw a pair of potato products (potatoes or fries) that varied in terms of aesthetic perfection. The human care information was identical to that in Study 4 and was provided for only the imperfect option. To manipulate human carelessness, we told participants that a human carelessly performed the steps in production for the imperfect option (see Web Appendix H). After viewing the pair of foods, individuals chose their preferred food option.

\section{Results}

We regressed food choice $(1=$ imperfect, $0=$ perfect $)$ on a contrast-coded variable for food processing $(1=$ processed, $-1=$ unprocessed), two dummy coded variables for information on imperfect with the control condition as the reference level, and the two-way interactions between food processing and the information on imperfect dummy codes using a logistic regression.

First, in support of $\mathrm{H} 2$ and as illustrated in Fig. 3, we find a positive simple effect of food processing within the control condition $\left(\beta=0.87, \chi^{2}(293)=14.75, p<.001\right)$, the human care information condition $\left(\beta=0.97, \chi^{2}(293)=18.18\right.$, $p<.001)$, and the human carelessness information condition $\left(\beta=1.18, \chi^{2}(293)=4.80, p=.029\right)$ indicating that preference for the imperfect (vs. perfect) option was greater with processed foods across all levels of information.

Next, we find a non-significant interaction between food processing and the human care dummy code $\left(\beta=0.09, \chi^{2}\right.$ $(293)=0.09, p=.767)$ and, in support of $\mathrm{H} 4$, there was a positive main effect of the human care dummy code $(\beta=$ $\left.0.79, \chi^{2}(293)=6.04, p=.014\right)$. With unprocessed foods, the simple effect of human care as compared to no information was non-significant $\left(\mathrm{P}_{\text {human_care }}=33.3 \%\right.$ vs. $\mathrm{P}_{\text {control }}=20.0 \%$; 
$\left.\beta=0.69, \chi^{2}(293)=2.25, p=.133\right)$ indicating that additional care information did not increase preference for the imperfect option relative to the control group. In contrast, providing information on the care involved in producing the imperfect processed food did increase preference for that option relative to when no information was provided $\left(\mathrm{P}_{\text {human_care }}=77.6 \% \mathrm{vs}\right.$. $\left.\mathrm{P}_{\text {control }}=58.8 \% ; \beta=0.88, \chi^{2}(293)=3.93, p=.047\right)$.

Finally, we find a non-significant interaction between food processing and the human carelessness dummy code $(\beta=$ 0.31, $\left.\chi^{2}(293)=0.27, p=.600\right)$ and a negative main effect of the human carelessness dummy code $\left(\beta=-2.18, \chi^{2}\right.$ $(293)=13.94, p<.001)$. In contrast to human care, the simple effect of human carelessness dummy code as compared to no information was negative for the unprocessed foods $\left(\mathrm{P}_{\text {carelessness }}=2.4 \% ; \beta=-2.48, \chi^{2}(293)=5.39, p=.020\right)$ and the processed foods $\left(\mathrm{P}_{\text {carelessness }}=18.0 \% ; \beta=-1.87, \chi^{2}\right.$ $(293)=16.21, p<.001)$.

\section{Discussion}

The results of Study 5 show that human care, rather than mere human involvement in production, drives preference for aesthetically imperfect foods. We found that informing participants that the imperfect option was produced carelessly by a human decreased preference for that option. This finding distinguishes our proposed process of human care from past research on the effects of effort (e.g., Franke and Schreier 2010). Next, Study 6 builds on the findings of Studies 4 and 5 by manipulating care information with care labels, which managers could easily implement. Importantly, Study 6 tests the effect of care information for both perfect and imperfect food options, which allows us to provide further evidence in support of our proposed process.

\section{Study 6: Manipulating care through labels}

The purpose of Study 6 is threefold. First, we wanted to generalize our findings to new sets of processed and unprocessed foods. Second, we wanted to employ realistic manipulations of care. Finally, we wanted to provide additional evidence that human care is an underlying mechanism driving food preferences. If, as we are predicting, care drives preferences for imperfect processed and unprocessed foods, then providing information about the care in production of the least preferred options (i.e., the imperfect unprocessed food and the perfect processed food) should attenuate the effect of processing on preference for the imperfect versus perfect food option.

\section{Design, participants, and procedure}

Study 6 had a 2 (food processing: processed vs. unprocessed) $\times 3$ (care information: sign on perfect option vs. sign on imperfect option vs. control/none) between-subjects design. We randomly assigned members of Prolific's online panel $(N=$ $186 ; 44.6 \%$ female, $54.9 \%$ male, $0.5 \%$ preferred not to say; $\mathrm{M}_{\mathrm{age}}=32.54$ ) to view and evaluate a pair of foods. We created the processed food (applesauce) by blending store-bought apples and water. The perfect applesauce had a uniform texture and color owing to the absence of apple chunks and skin. The imperfect applesauce had a non-uniform texture and color owing to the presence of apple chunks and skin. Participants in the unprocessed condition viewed a pair of store-bought apples that were the same weight and type but varied in appearance (i.e., uniform vs. non-uniform shape and texture). Appendix 3 provides images of the stimuli.

We manipulated care through the presence or absence of labels. When care information was present and individuals viewed a pair of processed foods, a "made-with-care" label
Fig. 3 Study 5 results

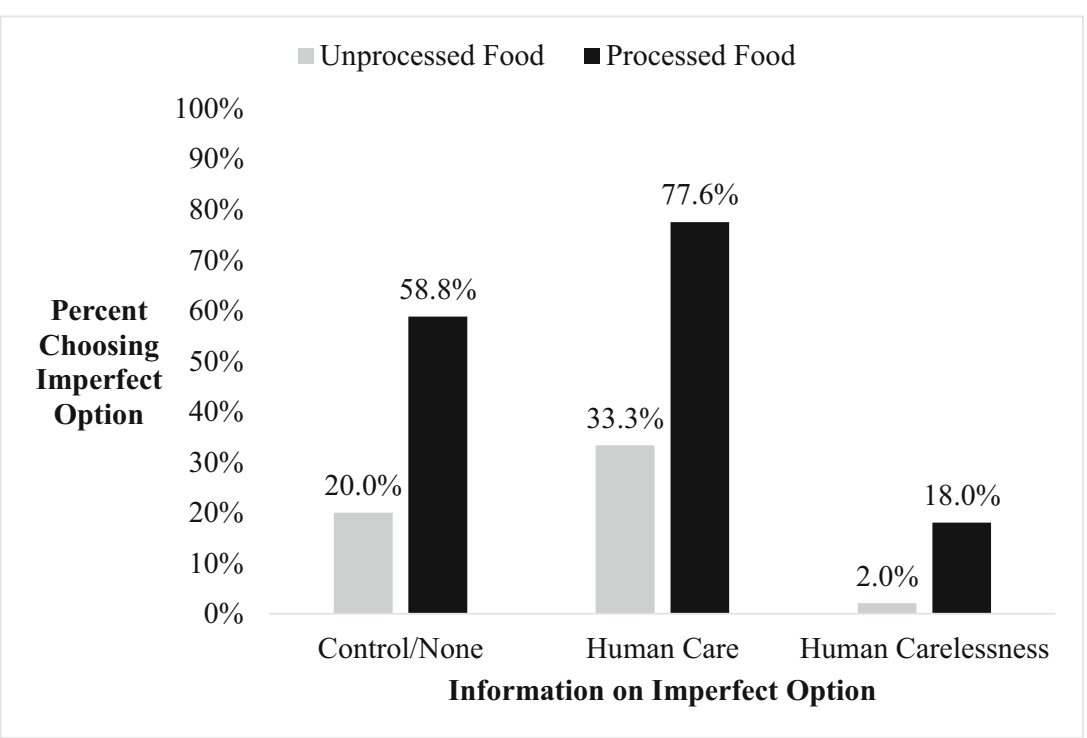


appeared next to one of the options. When care information was present and participants viewed a pair of unprocessed foods, a "grown-with-care" label appeared next to one of the options. In the control condition, no label was present. After viewing the food stimuli and care information, participants indicated which option they would prefer to eat ( $1=$ definitely option A, 7 = definitely option B). We coded preference so that higher numbers indicate greater preference for the imperfect option.

\section{Results}

A (food processing) $\mathrm{x}$ (care signage) ANOVA on preference for the imperfect option revealed a main effect of food processing $(\mathrm{F}$ $(1,180)=116.08, p<.001)$, a main effect of care information $(\mathrm{F}$ $(2,180)=28.91, p<.001)$, and a significant interaction $(\mathrm{F}(2$, $180)=6.17, p=.003$ ) (see Fig. 4). Consistent with H2, in the absence of care information participants had greater preference for the imperfect option when they viewed a set of processed foods than when they viewed a set of unprocessed foods $\left(\mathrm{M}_{\text {processed }}=4.50\right.$ vs. $\mathrm{M}_{\text {unprocessed }}=1.81 ; \mathrm{F}(5,180)=53.19$, $p<.001)$. In support of $\mathrm{H} 4$, follow-up planned contrast tests showed that preference for the imperfect unprocessed food (i.e., apple) increased when a care label was placed next to it compared to when no care information was present $\left(\mathrm{M}_{\text {label_imperfect }}=\right.$ 2.56 vs. $\left.\mathrm{M}_{\text {control }}=1.81 ; \mathrm{F}(5,180)=4.33, p=.039\right)$. Similarly, preference for the imperfect processed food (i.e., applesauce) decreased when a care label was placed next to the perfect applesauce compared to when no label was present $\left(\mathrm{M}_{\text {control }}=4.50\right.$ vs. $\left.\mathrm{M}_{\text {label_perfect }}=2.68 ; \mathrm{F}(5,180)=24.35, p<.001\right)$. Finally, we found that providing care information for the options that were less preferred in the control condition and the previous studies (i.e., the imperfect unprocessed food and the perfect processed food) attenuated the effect of processing $\left(\mathrm{M}_{\text {perfect processed }}=2.68\right.$ vs. $\left.\mathrm{M}_{\text {imperfect_unprocessed }}=2.56 ; \mathrm{F}(5,180)=0.10, p=.752\right)$. This

Fig. 4 Study 6 results finding supports our theorizing and suggests that providing human care information for options that consumers infer were produced with low levels of care can enhance preference for these items relative to items with higher levels of inferred care.

\section{Discussion}

The results of Study 6 provide evidence in support of our theorization that different attributions about the level of care in production are driving consumers' preferences. Specifically, the results suggest that providing care information on the aesthetically imperfect unprocessed foods and aesthetically perfect processed foods attenuates the effect of food processing on preference for imperfect options. Retailers could easily enhance or mitigate the influence of aesthetics on food choices by communicating information about care. In particular, our results suggest that the influence of explicit care labels is especially strong for processed foods.

\section{General discussion}

The seven studies reported here, conducted online and in the field, provide corroborating evidence that when choosing between two unprocessed foods consumers are more likely to select the aesthetically perfect (vs. imperfect) option. However, with processed foods, preferences shift toward the imperfect option. Furthermore, in Study 2, Study 4, Study 4's replication, and Study 6, we observe a complete preference reversal, with the majority of individuals preferring the perfect unprocessed food and the imperfect processed food. Similarly, the majority of participants in our pilot study preferred the imperfect (vs. perfect) processed food, and we observe a preference reversal in Study 1's field results. These findings are noteworthy, since the stimuli used in the pilot study were

- Unprocessed Food $\quad$ Processed Food

7

6 5

Preference for 4 Imperfect Option
5
4
3

1

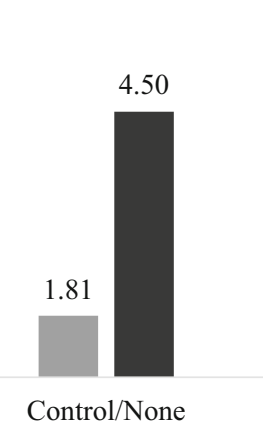

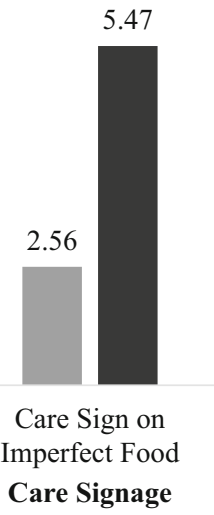

1.44

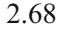

Care Sign on Perfect Food 
images of food items sourced from the internet and the stimuli used in Study 1 were foods available for sale. Our studies also provide evidence that perceived human care in production drives preferences, with imperfections signaling higher levels of care for processed foods but lower levels of care for unprocessed foods. We find that human care's effect on preferences differs from that of machine care or human involvement without care. Finally, as summarized in Table 3, the effects are robust to various types of aesthetic imperfections and diverse foods.

\section{Contributions, implications, and future research}

Theoretical contributions Theoretically, our findings help to reconcile prior research that shows enhanced aesthetics can have positive (Bloch 1995; Grewal et al. 2019) and negative effects on product evaluations and consumption decisions (Hoegg et al. 2010; Reich et al. 2018b; Wu et al. 2017). Specifically, we provide evidence for when (i.e., with processed foods) and why (i.e., owing to greater inferred human care) aesthetic imperfection can actually lead to an increase in preference. This contribution is important because the handful of studies documenting negative effects of enhanced product aesthetics have focused on product attribute evaluations (Hoegg et al. 2010), consumption, and enjoyment (Wu et al. 2017) and have used non-food stimuli (Reich et al. 2018b). Thus, our research extends the evidence for negative effects of enhanced aesthetics to the domain of consumer preferences between products. Furthermore, the finding that consumers prefer imperfect processed foods to perfect processed foods provides evidence of the subjective and context-specific nature of aesthetic judgments.
We also advance the marketing literature on the positive effects of perceived human presence (Fuchs et al. 2015; Morales 2005; Schroll et al. 2018) by offering evidence that aesthetic imperfections are a signal of human care in the production of processed and unprocessed foods. Care is inherently human (McCance et al. 1997). For example, the test of machine care information in Study 4 served as a comparison for the effects of human care information and also showed that human care is distinct from machine care. The negative effects of machine care information observed in Study 4 are consistent with prior research which suggests consumers negatively evaluate processed foods produced using industrial methods (Fernqvist and Ekelund 2014). Care is also distinct from constructs such as love and effort. While care can sometimes involve love, such as when one attends to a child or significant other, love is not a necessary condition for care (Lynch 2007). Love relates to feelings of emotional closeness, passion, and warmth (Fuchs et al. 2015), whereas care relates to protection (Perkins 2010). Care also differs from effort, which is the time and energy involved in production (Franke and Schreier 2010). While a positive relationship can exist between effort and care, as when one cares about a product and therefore puts effort into production, effort and care can also be unrelated or even negatively related, as when putting effort into sabotaging a research study (Huang et al. 2015). In addition to providing evidence in support of care as our process mechanism, we addressed several alternative explanations, including perceived freshness, healthiness, uniqueness, safety, scarcity, and artisanality. Furthermore, mechanisms such as negative self-perceptions, highlighted in other research on consumer avoidance of imperfections (Grewal et al. 2019), also would not explain the observed preference for aesthetically imperfect (vs. perfect) processed foods.

Table 3 Manipulations of aesthetic imperfections

Type of aesthetic imperfection

\begin{tabular}{|c|c|c|c|c|c|}
\hline \multirow{8}{*}{$\begin{array}{l}\text { Processed } \\
\text { Foods }\end{array}$} & Food Item & Study & Non-uniformity in shape & Non-uniformity in color & Non-uniformity in texture \\
\hline & Bread & Pilot & $\mathrm{X}$ & $\mathrm{X}$ & $\mathrm{X}$ \\
\hline & Cookie & & $\mathrm{X}$ & $\mathrm{X}$ & $\mathrm{X}$ \\
\hline & Cupcake & & & & $\mathrm{X}$ \\
\hline & Pizza & & & & $\mathrm{X}$ \\
\hline & Peanut butter cookies & 1 & $\mathrm{X}$ & & $\mathrm{X}$ \\
\hline & Fries & $2,3 a, 3 b, 4,5$ & & $\mathrm{X}$ & \\
\hline & Applesauce & $2,3 b, 4$ replication, 6 & & & $\mathrm{X}$ \\
\hline \multirow{7}{*}{$\begin{array}{l}\text { Unprocessed } \\
\text { Foods }\end{array}$} & Carrot & Pilot & $\mathrm{X}$ & $\mathrm{X}$ & $\mathrm{X}$ \\
\hline & Green apple & & $\mathrm{X}$ & & \\
\hline & Red apple & & $\mathrm{X}$ & $\mathrm{X}$ & \\
\hline & Tomato & & $\mathrm{X}$ & & $\mathrm{X}$ \\
\hline & Mandarins & 1 & $\mathrm{X}$ & $\mathrm{X}$ & $\mathrm{X}$ \\
\hline & Potato & $2,3 a, 3 b, 4,5$ & $\mathrm{X}$ & & \\
\hline & Apple & $2,3 b, 4$ replication, 6 & $\mathrm{X}$ & & \\
\hline
\end{tabular}


In light of the high standards for aesthetic perfection in fruits and vegetables at grocery stores, and the fact that food manufacturers design foods with slight aesthetic imperfections, we focused on the effects of relatively minor aesthetic imperfections to maintain external validity. Conceivably, more pronounced imperfections, including imperfections such as bruising or wormholes, would not signal human care in production and in fact might signal carelessness or neglect, likely decreasing preference. Thus, a curvilinear effect may result, where aesthetic imperfections increase preference for processed foods up to a certain point, beyond which they decrease preference for those foods. Future research should investigate how other types of imperfections as well as varying degrees of imperfection would influence choice. Consumer responses to aesthetics can also change through exposure (Cox and Cox 2002). After repeated exposure to aesthetically imperfect fruits and vegetables, consumers might become more accepting of them. Furthermore, customers differ on the importance of product aesthetics (Bloch et al. 2003) and attitudes toward food waste (Block et al. 2016). Future research should examine how repeated exposure to aesthetically imperfect food as well as individual differences might impact consumer preferences for aesthetically imperfect processed and unprocessed foods.

We also add to the literature on labeling effects by showing that care labels can enhance preference for less desirable foods (i.e., aesthetically imperfect whole foods, perfect processed foods). Prior research shows that labels can be effective in attracting attention and increasing purchase of foods (Dubois et al. 2020; Ikonen et al. 2020). Labeling a product as "handmade" (Fuchs et al. 2015), "natural" (Amos et al. 2014; Davis and Burton 2019), "organic" (Bauer et al. 2013; Lee et al. 2013), or even "ugly" (Mookerjee et al. 2019) positively influences consumer's product evaluations. The findings of our study show that "care" labels also have a positive effect on consumer preferences.

Finally, our findings contribute novel evidence that food processing influences consumers' evaluations of foods (Szocs and Lefebvre 2016). Most research on food processing has focused on understanding consumer perceptions of processed foods (Berry et al. 2017; Rozin 2005). We build on these studies by showing that the level of food processing influences consumers' attributions regarding aesthetic imperfections. Imperfections in processed foods signal human presence and, particularly, care in production. In contrast, imperfections in unprocessed foods signal a lack of human presence and care in production.

Practical implications Many restaurant chains and food manufacturers strive to produce uniform food items (Myers 2015). Steak ' $n$ Shake restaurants stopped serving hand-cut French fries because hand cutting introduced non-uniformity (Myers 2014). However, other restaurant chains and food manufacturers intentionally produce foods with non-uniform shapes, colors, and textures (i.e., aesthetic imperfections). Which tactic - producing aesthetically perfect or imperfect foodsyields the most favorable outcome? Our results suggest that aesthetic imperfections signal care in production for processed foods and, as a result, drive preferences. Thus, when designing processed foods to contain aesthetic imperfections is cost-effective, food manufacturers may benefit from this strategy. When costs prohibit a complete product redesign, our findings suggest that manufacturers can drive preferences by highlighting care in production. Nabisco seems to be leveraging this strategy by emphasizing that the wheat used in Triscuit Thin Crisps Parmesan Garlic crackers was "grown with care" (see Appendix 4).

Following Hoegg et al. (2010), we limited our focus to contexts in which individuals compare a more and less aesthetically perfect version of the same food to highlight aesthetic imperfections. We also attempted to minimize the effects of stimuli-specific factors in three ways. First, in the pilot study we used stimuli sourced from the internet. Additionally, we replicated the effects in a field study with two brands of peanut butter cookies (processed foods) and mandarin oranges (unprocessed foods) that were for sale in the store. While the results of the pilot study and Study 1 suggest our results are robust to various imperfections and exist with real products, the stimuli employed varied in ways that may have introduced confounding factors, such as different ingredients. Thus, a second way we minimized the effects of specific stimuli was by using two different pairs of stimuli created by a photographer who was blind to the experimental hypotheses in Studies $2-5$. Finally, in Study 6, we used unprocessed apples purchased from a grocery store and mechanically processed them into perfect and imperfect versions of applesauce. While we zealously attempted to address stimulus issues, future researchers should replicate our effects with other products and types of aesthetic imperfections.

Beyond offering guidance for the design and promotion of processed foods, our findings suggest tactics to increase consumers' acceptance of aesthetically imperfect produce. First, grocery store managers wanting to minimize waste of aesthetically imperfect fruits and vegetables could process the foods that shoppers are unlikely to select and serve them on salad bars as aesthetically imperfect processed foods (e.g., applesauce, salsa, and coleslaw). We suggest this tactic because of the finding that consumers are more likely to prefer aesthetically imperfect foods when they are processed rather than unprocessed. Similarly, chefs or restaurant managers wanting to use aesthetically imperfect unprocessed fruits (e.g., asymmetric apples) could process the foods into juices for use as bar mixers, fruit spreads, desserts, or daily specials. Additionally, marketers can 
boost preference for aesthetically imperfect produce by providing information about the human care involved in producing the food, since the results of Studies 4, 5, and 6 show that highlighting human care increases preference. We find that labels such as "made with care" or "grown with care" might be a cost-effective tactic to increase preference of less desirable foods. These labels could easily be placed on in-store signage or directly on products and packages (e.g., as stickers). Given that food waste is a societal-level issue, these tactics could prove useful in addressing a macro-level problem (Webster and Lusch 2013).

We recommend that future research investigate other visual, verbal, and contextual cues that implicitly serve as care labels. For instance, imperfections often occur in produce sold at farmers' markets, and many individuals prefer locally produced fruits and vegetables that trace back to a farmer (Murdoch and Miele 1999; Reich et al. 2018a). Conceivably, the farmers' market or the visual presence of a local farmer at a market may act as human care information did in Study 4, exerting a positive influence on preference for imperfect products. Would merely linking food to a human through imagery (e.g., a baker or farmer) or through verbal cues (e.g., Grandma's Cookies) on packaging signal care? Future research should explore this question.

Policy and consumer advocacy implications As described in the introduction, farmers, retailers, and consumers discard millions of pounds of safe-to-eat unprocessed fruits and vegetables each year because they exhibit aesthetic imperfections (Bratskeir 2015). Based on the proposed and validated underlying process, we have identified and successfully tested strategies to increase preference for aesthetically imperfect unprocessed fruits and vegetables. The results of our research suggest that highlighting the involvement of humans in the production process increases preference for aesthetically imperfect unprocessed fruits and vegetables, potentially contributing to a reduction in the amount of produce wasted annually. Policymakers may consider launching public campaigns highlighting the relevance of human care in the production process of unprocessed foods. Such campaigns could support the sales of aesthetically imperfect produce to reduce the amount of imperfect fruits and vegetables wasted (Van Ittersum et al. 2007). Future research on the effectiveness of such public campaigns is warranted.

Our research offers insights to increase the sales of aesthetically imperfect fruits and vegetables to reduce the economic and social costs associated with food waste. However, our research also explains why companies produce and market processed products, like pizza, turkey, and egg patties, with aesthetic imperfections. That is, we show that consumers infer human care during production based on aesthetic imperfections in processed foods, even when these imperfections are part of the product design. While effective, some moral questions can be raised. If and to what extent can product design be inferred as 'misleading'? There is a growing realization that manufacturers are misleading the public by labeling their products as "natural", "artisanal" and "homemade" (Boseley 2018). The European Consumer Organization (BEUC) calls for more regulation of food labeling. In the USA, the USDA regulates food labeling, including these so called "special statements and claims" (USDA 2020). The USDA thus acknowledges that labels, as well as pictures, colors and even logo's may be misleading. We recommend that policymakers also consider the potential effects of aesthetic imperfections in processed foods as a "special statement and claim". Given that our research suggests that these imperfections increase the perceived artisanality of the products, it appears worthwhile to further investigate their perceived level of misleadingness among consumers.

Related to this, we call on consumers and consumer advocates to be cognizant of how "care labels" might influence their product preferences. Manufacturers can place care labels on products without requiring that the products meet any specific criteria. Thus, consumers may want to assess the care involved in making or growing a product through additional information, such as through blockchain technology, rather than on the basis of a care label alone.

\section{Overall conclusions}

All in all, our research expands our understanding of consumer responses to product aesthetics, provides evidence for the importance of care inferences in food choices, and has the potential to reduce food waste and contribute to more sustainable business practices. At the same time, our research suggests that the production of aesthetically imperfect processed products may warrant some further scrutiny from policymakers.

\section{Appendix 1: Examples of stimuli used in Study 2}

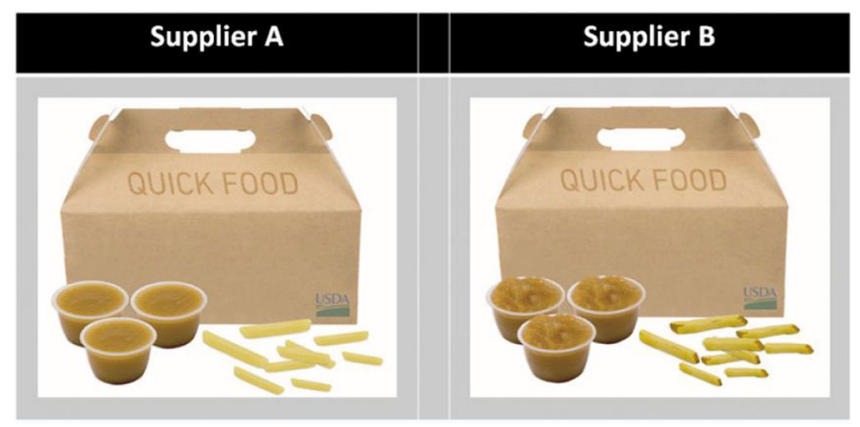


Processed foods (imperfect shown as B).

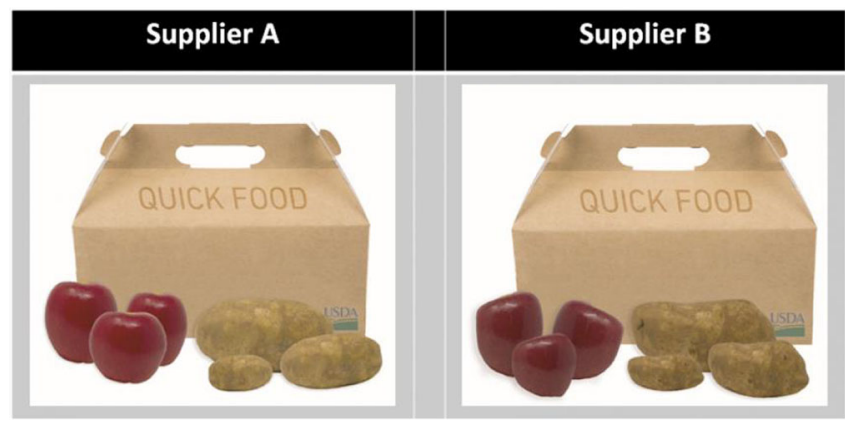

Unprocessed foods (imperfect shown as B)

\section{Appendix 2: Measures used in pretest and studies}

\section{Measures used in Stimuli Creation pretest}

\section{Aesthetic Perfection:}

The shape of the food is uniform.

The shape of the food is consistent.

The shape of the food varies (i.e., is inconsistent). (reversed).

The color of the food is uniform.

The color of the food is consistent.

The color of the food varies (i.e., is inconsistent). (reversed).

The texture of the food is uniform.

The texture of the food is consistent.

The texture of the food varies (i.e., is inconsistent). (reversed).

$(1$ = Strongly Disagree, $7=$ Strongly Agree $)$

Taste:

How do you think the pictured food would taste?

( 1 = Not at all Sweet/Not at all Bitter/Not at all Sour/Not at all Savory/Not at all Creamy, $7=$ Very Sweet/Very Bitter/ Very Sour/Very Savory/Very Creamy)

\section{Measures used in Studies 3a, 3b, and Study 4 pretest}

\section{Preference:}

Which of the foods pictured above would you prefer to have? (1 = Definitely Food A, 7 = Definitely Food B)

\section{Human Care:}

Which food received more human care when it was produced?
Which food received more human attention when it was produced?

Which food was neglected by a human (i.e., not cared for by a human) during the production process? (reversed).

$(1=$ Definitely Food A, $7=$ Definitely Food B $)$

Machine Care (used in Study 3b):

Which food received more machine care when it was produced?

Which food received more machine attention when it was produced?

Which food was neglected by a machine (i.e., not cared for by a machine) during the production process? (reversed).

$(1=$ Definitely Food A, 7 = Definitely Food B)

\section{Appendix 3: Examples of stimuli used in Study 6}

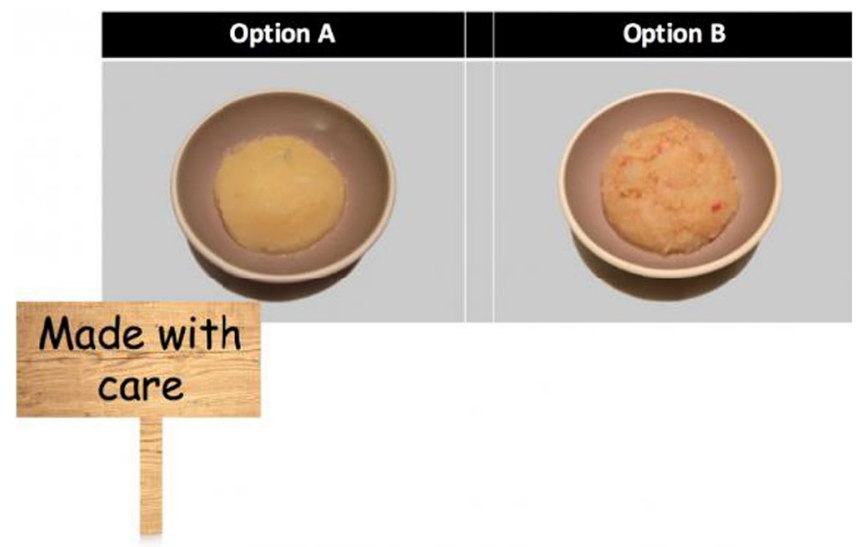

Processed foods (applesauce) with care signage on perfect option (imperfect shown as B).

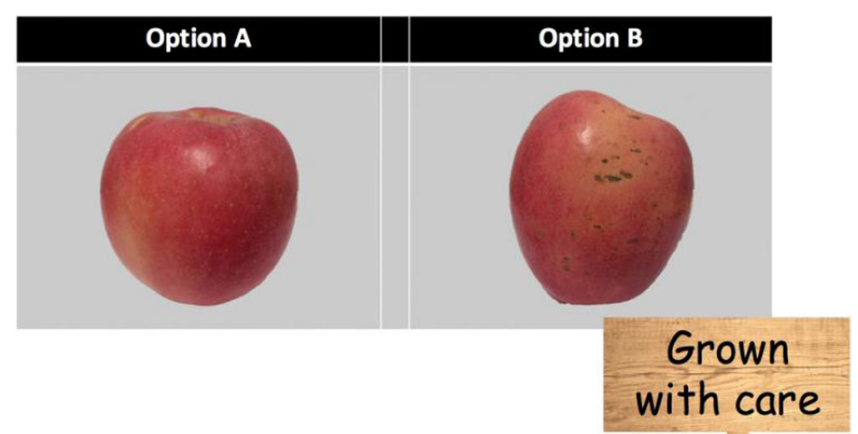


Unprocessed foods (apples) with care signage on imperfect option (imperfect shown as B)

\section{Appendix 4: Nabisco highlights "grown with care"}
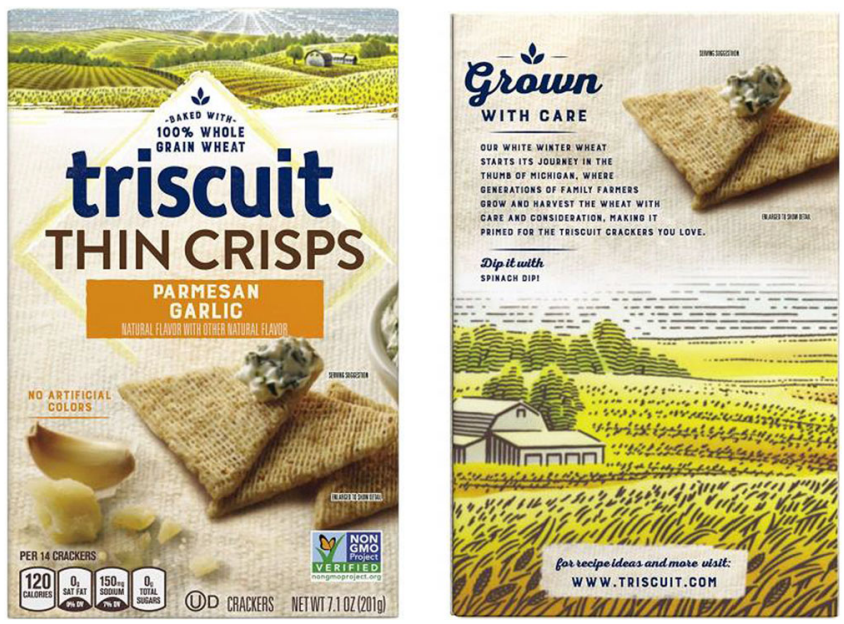

Supplementary Information The online version contains supplementary material available at https://doi.org/10.1007/s11747-021-00783-1.

Open Access This article is licensed under a Creative Commons Attribution 4.0 International License, which permits use, sharing, adaptation, distribution and reproduction in any medium or format, as long as you give appropriate credit to the original author(s) and the source, provide a link to the Creative Commons licence, and indicate if changes were made. The images or other third party material in this article are included in the article's Creative Commons licence, unless indicated otherwise in a credit line to the material. If material is not included in the article's Creative Commons licence and your intended use is not permitted by statutory regulation or exceeds the permitted use, you will need to obtain permission directly from the copyright holder. To view a copy of this licence, visit http://creativecommons.org/licenses/by/4.0/.

\section{References}

Abouab, N., \& Gomez, P. (2015). Human contact imagined during the production process increases food naturalness perceptions. Appetite, 91, 273-277.

Amos, C., Pentina, I., Hawkins, T. G., \& Davis, N. (2014). "Natural" labeling and consumers' sentimental pastoral notion. Journal of Product \& Brand Management, 23, 268-281.

Arnould, E. J., \& Price, L. L. (2006). Market-oriented ethnography revisited. Journal of Advertising Research, September, 251-262.

Ashe, S. (2019). 13 things you didn't know about Oreo cookies. Retrieved October 24, 2020 from https://www.insider.com/ interesting-facts-about-oreo-2018-7

Aschemann-Witzel, J., Gimenez, A., \& Ares, G. (2018). Consumer instore choice of suboptimal food to avoid food waste: The role of food category, communication, and perception of quality dimensions. Food Quality \& Preference, 68, 29-39.

Aschemann-Witzel, J., Jensen, J. H., Jensen, M. H., \& Kulikovskaja, V. (2017). Consumer behaviour towards price-reduced suboptimal foods in the supermarket and the relation to food waste in households. Appetite, 116, 246-258.

Aschemann-Witzel, J., Otterbring, T., de Hooge, I. E., Normann, A., Rohm, H., Almli, V., \& Oostindjer, M. (2019). The who, where and why of choosing suboptimal foods: Consequences for tackling food waste in store. Journal of Cleaner Production, 236, 117596.

Associated Press (2013). Food companies spend big money to achieve 'homemade' look as consumers drift from overly processed fare. Retrieved November 8, 2016 from https://archive.triblive.com/ news/wire-stories/food-companies-spend-big-money-to-achievehomemade-look-as-consumers-drift-from-overly-processed-fare/

Baker, G. A. (1999). Consumer preferences for food safety attributes in fresh apples: Market segments, consumer characteristics, and marketing opportunities. Journal of Agricultural and Resource Economics, 24, 80-97.

Bauer, H. H., Heinrich, D., \& Schäfer, D. B. (2013). The effects of organic labels on global, local and private brands: More hype than substance? Journal of Business Research, 66, 1035-1043.

Becker, G. M., DeGroot, M. H., \& Marschak, J. (1964). Measuring utility by a single-response sequential method. Behavioral Science, 9, 226 232.

Berry, C., Burton, S., \& Howlett, E. (2017). It's only natural: The mediating impact of consumers' attribute inferences on the relationships between product claims, perceived product healthfulness, and purchase intentions. Journal of the Academy of Marketing Science, 45, 698-719.

Bloch, P. H. (1995). Seeking the ideal form: Product design and consumer response. Journal of Marketing, 59, 16-29.

Bloch, P. H., Brunel, F. F., \& Arnold, T. J. (2003). Individual differences in the centrality of visual product aesthetics: Concept and measurement. Journal of Consumer Research, 29, 551-565.

Block, L. G., Keller, P. A., Vallen, B., Williamson, S., Birau, M. M., Grinstein, A., Haws, K. L., LaBarge, M. C., Lamberton, C., Moore, E. S., Moscato, E. M., Reczek, R. W., \& Tangari, A. H. (2016). The squander sequence: Understanding food waste at each stage of the consumer decision-making process. Journal of Public Policy \& Marketing, 35, 292-304.

Boerop, L., \& Moynihan, Q. (2020). We visited a meat-processing factory to find out exactly how McDonald's hamburgers are made. Retrieved October 24, 2020 from https://www.businessinsider. com/i-went-to-a-mcdonalds-factory-and-saw-how-the-burgers-arereally-made-2018-10

Boseley, S. (2018). Shoppers being misled by labels that claim food is 'artisinal' or homemade. Retrieved January 28, 2021 from https:// www.theguardian.com/money/2018/jun/14/making-an-honestcrust-consumers-routinely-conned-by-food-labels

Bratskeir, K. (2015). Six billion pounds of perfectly edible produce is wasted each year, simply because it's ugly. Retrieved November 9, 2016 from https://www.huffpost.com/entry/food-waste-uglyfruits-and-vegs-dont-judge_n_7309432

Bunn, D., Feenstra, G., Lynch, L., \& Sommer, R. (1990). Consumer acceptance of cosmetically imperfect produce. Journal of Consumer Affairs, 24, 268-279.

Buzby, J. C., Hyman, J., Stewart, H., \& Wells, H. F. (2011). The value of retail- and consumer-level fruit and vegetable losses in the United States. Journal of Consumer Affairs, 45, 492-415.

Cox, D., \& Cox, A. D. (2002). Beyond first impressions: The effects of repeated exposure on consumer liking of visually complex and 
simple product designs. Journal of the Academy of Marketing Science, 30, 119-130.

Choi, C. (2013). Food companies work to make it look natural. Retrieved November 9, 2016 from http://www.sandiego-uniontribune.com/ sdut-food-companies-work-to-make-it-look-natural-2013jun17story.html

Cooremans, K., \& Geuens, M. (2019). Same but different: Using anthropomorphism in the battle against food waste. Journal of Public Policy \& Marketing, 38, 232-245.

Crolic, C., Zheng, Y., Hoegg, J., \& Alba, J. W. (2019). The influence of product aesthetics on consumer inference making. Journal of the Association for Consumer Research, 4, 398-408.

Davis, C. D., \& Burton, S. (2019). Making bad look good: The counterpersuasive effects of natural labels on (dangerous) vice goods. Journal of Business Research, 104, 271-282.

de Hooge, I. E., Oostindjer, M., Aschemann-Witzel, J., Normann, A., Mueller-Loose, S., \& Lengard-Almli, V. (2017). This apple is too ugly for me!: Consumer preferences for suboptimal food products in the supermarket and at home. Food Quality and Preference, 56, 80 92.

Dubois, P., Albuquerque, P., Allais, O., Bonnet, C., Bertail, P., Combris, P., ... \& Chandon, P. (2020). Effects of front-of-pack labels on the nutritional quality of supermarket food purchases: Evidence from a large-scale randomized controlled trial. Journal of the Academy of Marketing Science.

Evans, G., de Challemaison, B., \& Cox, D. N. (2010). Consumers' ratings of the natural and unnatural qualities of foods. Appetite, 54, 557563.

Fernqvist, F., \& Ekelund, L. (2014). Credence and the effect on consumer liking of food-a review. Food Quality and Preference, 32, 340-353.

Franke, N., \& Schreier, M. (2010). Why customers value self-designed products: The importance of process effort and enjoyment. Journal of Product Innovation Management, 27, 1020-1031.

Fuchs, C., Schreier, M., \& van Osselaer, S. (2015). The handmade effect: What's love got to do with it? Journal of Marketing, 79, 98-110.

Grewal, D., Noble, S. M., Roggeveen, A. L., \& Nordfält, J. (2020). The future of in-store technology. Journal of the Academy of Marketing Science, 48, 96-113.

Grewal, L., Hmurovic, J., Lamberton, C., \& Reczek, R. W. (2019). The self-perception connection: Why consumers devalue unattractive produce. Journal of Marketing, 83, 89-107.

Hagen, L. (2020). Pretty healthy food: How and when aesthetics enhance perceived healthiness. Journal of Marketing, forthcoming.

Hagtvedt, H., \& Patrick, V. (2008). Art infusion: The influence of visual art on the perception and evaluation of consumer products. Journal of Marketing Research, 45, 379-389.

Hagtvedt, H., \& Patrick, V. (2014). Consumer response to overstyling: Balancing aesthetics and functionality in product design. Psychology \& Marketing, 31, 518-525.

Hayes, A. F. (2012). PROCESS: A versatile computational tool for observed variable mediation, moderation, and conditional process modeling. Retrieved October 1, 2016 from http://www.afhayes. com/public/process2012.pdf

Helmert, J. R., Symmank, C., Pannasch, S., \& Rohm, H. (2017). Have an eye on the buckled cucumber: An eye tracking study on visually suboptimal foods. Food Quality and Preference, 60, 40-47.

Huang, J. L., Liu, M., \& Bowling, N. A. (2015). Insufficient effort responding: Examining an insidious confound in survey data. Journal of Applied Psychology, 100, 828-845.

Hoegg, J., Alba, J. W., \& Dahl, D. W. (2010). The good, the bad and the ugly: Influence of aesthetics on product feature judgments. Journal of Consumer Psychology, 20, 419-430.
Ikonen, I., Sotgiu, F., Aydinli, A., \& Verlegh, P. W. (2020). Consumer effects of front-of package nutrition labeling: An interdisciplinary meta-analysis. Journal of the Academy of Marketing Science, 48, 360-338.

Kader, A. A. (1986). Effects of post-harvest handling procedures on tomato quality. Acta Horticulturae, 190, 209-222.

Koo, M., Oh, H., \& Patrick, V. M. (2019). From oldie to goldie: Humanizing old produce enhances its appeal. Journal of the Association for Consumer Research, 4, 337-351.

Lawson, B. (1983). How designers think. Westfield: Eastview Editions.

Lee, W. J., Shimizu, M., Kniffin, K. M., \& Wansink, B. (2013). You taste what you see: Do organic labels bias taste perceptions? Food Quality and Preference, 29, 33-39.

Loebnitz, N., \& Grunert, K. G. (2015). The effect of food shape abnormality on purchase intentions in China. Food Quality and Preference, 40, 24-30.

Loebnitz, N., \& Grunert, K. G. (2018). The impact of abnormally shaped vegetables on consumers' risk perception. Food Quality and Preference, 63, 80-88.

Loebnitz, N., Schuitema, G., \& Grunert, K. G. (2015). Who buys oddly shaped food and why? Impacts of food shape abnormality and organic labeling on purchase intentions. Psychology \& Marketing, 32, 408-441.

Lynch, K. (2007). Love labour as a distinct and non-commodifiable form of care labour. The Sociological Review, 55, 550-570.

Makhal, A., Thyne, M., Robertson, K., \& Mirosa, M. (2020). I don't like wonky carrots: An exploration of children's perceptions of suboptimal fruits and vegetables. Journal of Retailing and Consumer Services, 54, 101945.

McCance, T. V., McKenna, H. P., \& Boore, J. R. P. (1997). Caring: Dealing with a difficult concept. International Journal of Nursing Studies, 34, 241-248.

Moisio, R., Arnould, E. J., \& Price, L. (2004). Between mothers and markets: Constructing family identity through homemade food. Journal of Consumer Culture, 4, 361-384.

Mookerjee, A., Cornil, Y., \& Hoegg, J. (2019). Stating the obvious: How "ugly" labels can increase purchase of unappealing produce and reduce waste. In R. Bagchi, L. Block, \& L. Lee (Eds.), Advances in consumer research (pp. 158-163). Duluth: Association for Consumer Research.

Morales, A. C. (2005). Giving firms an "e" for effort: Consumer responses to high-effort firms. Journal of Consumer Research, 31, 806-812.

Morse, J. M., Solberg, S. M., Neander, W. L., Bottorff, J. L., \& Johnson, J. L. (1990). Concepts of caring and caring as a concept. Advances in Nursing Science, 13, 1-14.

Moshagen, M., Musch, J., \& Göritz, A. S. (2009). A blessing, not a curse: Experimental evidence for beneficial effects of visual aesthetics on performance. Ergonomics, 52, 1311-1320.

Murdoch, J., \& Miele, M. (1999). 'Back to nature': Changing 'worlds of production' in the food sector. Sociologia Ruralis, 39, 465-483.

Myers, D. (2014). Great news Shake Shack is bringing back crinkle-cut fries. Retrieved January 2, 2020 from https:/www.thedailymeal. $\mathrm{com} /$ great-news-shake-shack-bringing-back-crinkle-cut-fries

Myers, D. (2015). How do chain restaurants keep food so consistent across locations? Retrieved January 2, 2020 from https://www. thedailymeal.com/eat/how-do-chain-restaurants-keep-food-soconsistent-across-all-locations

Nassauer, J. I. (1988). The aesthetics of horticulture: Neatness as a form of care. Hortscience, 23, 973-977.

Nenkov, G. Y., \& Scott, M. L. (2014). "So cute I could eat it up": Priming effects of cute products on indulgent consumption. Journal of Consumer Research, 41, 326-341. 
Newman, G. E., \& Bloom, P. (2012). Art and authenticity: The importance of originals in judgments of value. Journal of Experimental Psychology: General, 141, 558-569.

Norman, D. A. (2004). Emotional design: Why we love (or hate) everyday things. New York: Basic Books.

Paaki, M., Aaltojarvi, I., Sandell, M., \& Hopia, A. (2019). The importance of the visual aesthetics of colours in food at a workday lunch. International Journal of Gastronomy and Food Science, 16, 100131.

Paxson, H. (2013). The life of cheese: Crafting food and value in America. Berkeley: University of California Press.

Perkins, H. E. (2010). Measuring love and care for nature. Journal of Environmental Psychology, 30, 455-463.

Phillips, J. (2017). Why fruit has a fake wax coating. Retrieved June 24, 2017 from https:/www.theatlantic.com/technology/archive/2017/ 04/why-fruit-has-a-fake-wax-coating/524619/

Process Engineering (2014). Homemade in the factory. Retrieved January 2, 2020 from http://processengineering.co.uk/article/2019302/ homemade-in-the-fact

Reich, B. J., Beck, J. T., \& Price, J. (2018a). Food as ideology: Measurement and validation of locavorism. Journal of Consumer Research, 45, 849-868.

Reich, T., Kupor, D. M., \& Smith, R. K. (2018b). Made by mistake: When mistakes increase product preference. Journal of Consumer Research, 44, 1085-1103.

Reimann, M., Zaichkowsky, J., Neuhaus, C., Bender, T., \& Weber, B. (2010). Aesthetic package design: A behavioral, neural, and psychological investigation. Journal of Consumer Psychology, 20, 431441.

Roosen, J., Fox, J. A., Hennessy, D. A., \& Schrieber, A. (1998). Consumers' valuation of insecticide use restrictions: An application to apples. Journal of Agricultural and Resource Economics, 23, $367-384$.

Royte, E. (2016). How 'ugly' fruits and vegetables can help solve world hunger. National Geographic Retrieved November 25, 2019 from https://www.nationalgeographic.com/magazine/2016/03/globalfood-waste-statistics/

Rozin, P. (2005). The meaning of "natural": Process more important than content. Psychological Science, 16, 652-658.

Schifferstein, H. N. J., Wehrle, T., \& Carbon, C. (2019). Consumer expectations for vegetables with typical and atypical colors: The case of carrots. Food Quality and Preference, 72, 98-108.

Schroll, R., Schnurr, B., \& Grewal, D. (2018). Humanizing products with handwritten typeface. Journal of Consumer Research, 45, 648-672.

Short, J., Williams, E., \& Christie, B. (1976). The social psychology of telecommunications. Toronto: Wiley.

Steenkamp, J. B. E. M., \& van Trijp, C. M. (1996). Quality guidance: A consumer-based approach to food quality improvement using partial least squares. European Review of Agricultural Economics, 23, 195-215.

Symmank, C., Zahn, S., \& Rohm, H. (2018). Visually suboptimal bananas: How ripeness affects consumer expectation and perception. Appetite, 120, 472-481.

Szocs, C., \& Lefebvre, S. (2016). The blender effect: Physical state of food influences healthiness perceptions and consumption decisions. Food Quality and Preference, 54, 152-159.

Townsend, C. (2017). The price of beauty: Differential effects of design elements with and without cost implications in nonprofit donor solicitations. Journal of Consumer Research, 44, 794-815.

USDA (2020). FSIS compliance guideline for label approval. Retrieved January 29, 2021 from https://www.fsis.usda.gov/wps/wcm/ connect/bf170761-33e3-4a2d-8f86-940c2698e2c5/LabelApproval-Guide.pdf?MOD=AJPERES

van Giesen, R. I., \& de Hooge, I. E. (2019). Too ugly, but I love its shape: Reducing food waste of suboptimal products with authenticity (and sustainability) positioning. Food Quality and Preference, 75, 249259.

Van Ittersum, K., Pennings, J. M. E., Wansink, B., \& Van Trijp, H. C. M. (2007). The validity of attribute-importance measurement: A review. Journal of Business Research, 60(11), 1177-1190.

Webster, F. E., \& Lusch, R. F. (2013). Elevating marketing: Marketing is dead! Long live marketing! Journal of the Academy of Marketing Science, 41, 389-399.

White, K., Lin, L., Dahl, D. W., \& Ritchie, R. J. R. (2016). When do consumers avoid imperfections? Superficial packaging damage as a contamination cue. Journal of Marketing Research, 53, 110-123.

Wiecek, A., Wentzel, D., \& Landwehr, J. (2019). The aesthetic fidelity effect. International Journal of Research in Marketing, 36, 542557.

Wu, F., Samper, A., Morales, A. C., \& Fitzsimons, G. J. (2017). It's too pretty to use! When and how enhanced product aesthetics discourage usage and lower consumption enjoyment. Journal of Consumer Research, 44, 651-672.

Yamamoto, M., \& Lambert, D. R. (1994). The impact of product aesthetics on the evaluation of industrial products. Journal of Product Innovation Management, 11, 309-324.

Yue, C., Jensen, H. H., Mueller, D. S., Nonnecke, G. R., Bonnet, D., \& Gleason, M. L. (2007). Estimating consumers' valuation of organic and cosmetically damaged apples. HortScience, 42, 1366-1371.

Zellner, D. A., Siemers, E., Teran, V., Conroy, R., Lankford, M., Agrafiotis, A., Ambrose, L., \& Locher, P. (2011). Neatness counts: How plating effects liking for the taste of food. Appetite, 57, 642648.

Publisher's note Springer Nature remains neutral with regard to jurisdictional claims in published maps and institutional affiliations. 